This document was prepared in conjunction with work accomplished under Contract No. DE-AC09-96SR18500 with the U. S. Department of Energy.

\title{
DISCLAIMER
}

This report was prepared as an account of work sponsored by an agency of the United States Government. Neither the United States Government nor any agency thereof, nor any of their employees, nor any of their contractors, subcontractors or their employees, makes any warranty, express or implied, or assumes any legal liability or responsibility for the accuracy, completeness, or any third party's use or the results of such use of any information, apparatus, product, or process disclosed, or represents that its use would not infringe privately owned rights. Reference herein to any specific commercial product, process, or service by trade name, trademark, manufacturer, or otherwise, does not necessarily constitute or imply its endorsement, recommendation, or favoring by the United States Government or any agency thereof or its contractors or subcontractors. The views and opinions of authors expressed herein do not necessarily state or reflect those of the United States Government or any agency thereof. 
WSRC-TR-2005-00563

\title{
FLUENT Test and Verification Document
}

\author{
Si Young Lee \\ Richard A. Dimenna
}

December 2005

Westinghouse Savannah River Company

Savannah River National Laboratory

Aiken, SC 29808

Prepared for the U.S. Department of Energy

Under Contract No. DE-AC09-96SR18500

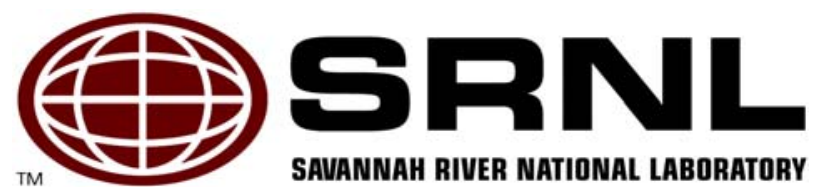


WSRC-TR-2005-00563

DISCLAIMER

This report was prepared by Westinghouse Savannah River Company (WSRC) for the United States Department of Energy under Contract No. DE-AC09-96SR18500 and is an account of work performed under that contract. Neither the United States Department of Energy, nor WSRC, nor any of their employees makes any warranty, expressed or implied, or assumes any legal liability or responsibility for the accuracy, completeness, or usefulness, of any information, apparatus, or product or process disclosed herein or represents that its use will not infringe privately owned rights. Reference herein to any specific commercial product, process, or service by trademark, name, manufacturer or otherwise does not necessarily constitute or imply endorsement, recommendation, or favoring of same by WSRC or by the United States Government or any agency thereof. The views and opinions of the authors expressed herein do not necessarily state or reflect those of the United States Government or any agency thereof.

Printed in the United States of America

Prepared For

U.S. Department of Energy 
WSRC-TR-2005-00563

Keywords: Computational Fluid Dynamics, FLUENT, Flow Patterns,

Flow Obstructions

\title{
FLUENT Test and Verification Document
}

\author{
Si Young Lee \\ Richard A. Dimenna
}

December 2005

Westinghouse Savannah River Company

Savannah River National Laboratory

Aiken, SC 29808

Prepared for the U.S. Department of Energy Under Contract No. DE-AC09-96SR18500

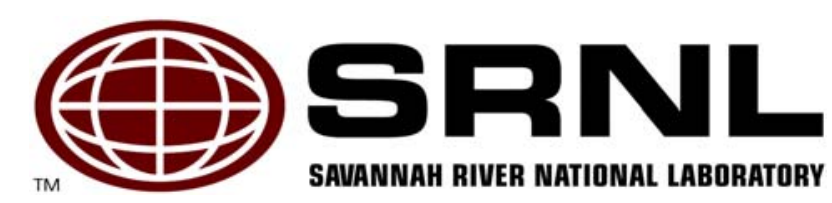




\section{Review and Approvals}
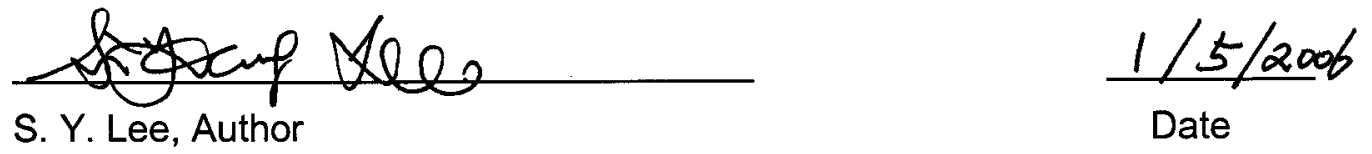

Eng. Modeling and Simulation Group, SRNL

$1 / 05 / 2006$

Date

R. A. Dimenna, Coauthor

Eng. Modeling and Simulation Group, SRNL
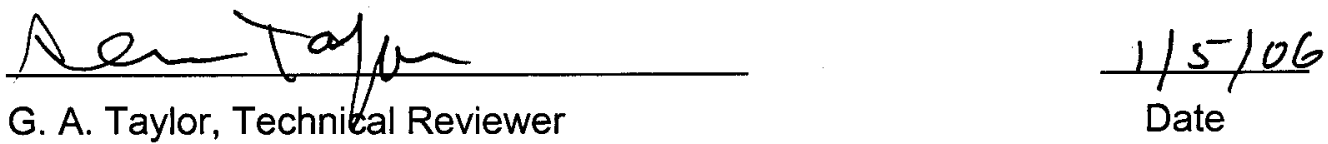

G. A. Taylor, Technilal Reviewer

Environmental Assessment \& Performance Modeling Group, SRNL

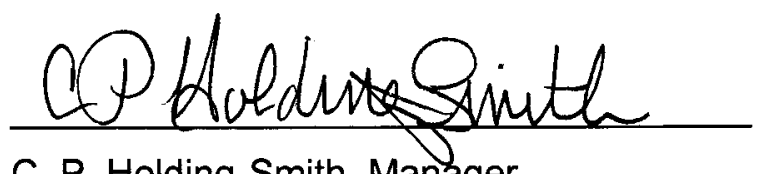

C. P. Holding-Smith, Manager

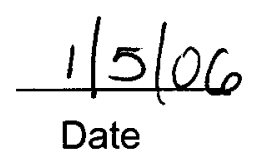

Eng. Modeling and Simulation Group, SRNL

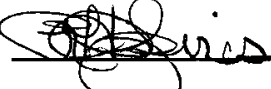

R. H. Spires, Project Owner

$1-11-06$

Date

Tank 48 Disposition Project / LWDP 


\section{Table of Contents}

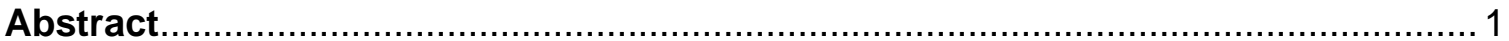

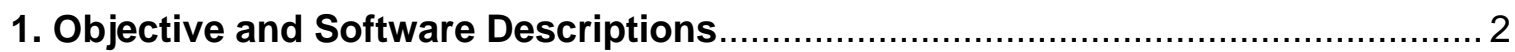

2. Software Installation and Computing Platform ….......................................... 2

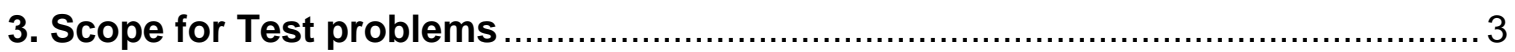

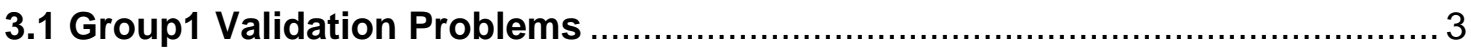

- Turbulent isothermal flow in a pipe

- Two-dimensional natural convection inside a rectangular enclosure with specified boundary temperatures

3.2 Group2 Validation Problems

- $\kappa-\varepsilon$ model evaluation for three-dimensional turbulent free jet

- $\kappa-\varepsilon$ turbulent model evaluation in a three-dimensional ventilated room

- Turbulent mixing evaluation in a three-dimensional axi-symmetric jet

3.3 Group3 Validation Problems

- Impact of Small Flow Obstructions in a Large Flow Channel

- Flow Obstruction Effects Due to the Presence of Cooling Coils

4. Summary

5. References 


\section{List of Figures}

Figure 1. Isothermal flow in a circular pipe....................................................... 3

Figure 2. Flow patterns at various distances from the air entrance in 0.2-m pipe........... 4

Figure 3. Radial velocity distributions for various distances from the entrance demonstrating that flow is fully developed at about 15 diameters' distance from the pipe inlet, consistent with the literature information [6].................... 5

Figure 4. Natural convection inside a slit enclosure ................................................ 7

Figure 5. Geometry for natural convection model. ................................................ 8

Figure 6. Comparison of FLUENT6 predictions with theoretical predictions for Case1 . 10

Figure 7. Comparison of FLUENT6 predictions with theoretical predictions for Case2 .11

Figure 8. Schematic diagram of the water jet system conducted by Kiser (1963) and CFD three-dimensional modeling and computational domain with two symmetrical planes

Figure 9. Comparison of the turbulent jet axial velocity predicted by the CFD code with the test data and the published correlations available in the literature.

Figure 10. Geometric arrangements and modeling coordinate system of the ventilated room used by Nielsen et al.'s experiment [1978] and Nielsen [1976]....

Figure 11. Flow patterns at the middle plane of the Case-1 ventilated room conducted by Nielsen et al. (1978).

Figure 12. Comparison results of non-dimensional maximum velocity magnitude along the incoming flow direction from the air inlet plane at $\mathrm{Re}=5,000$ inlet flow (inlet velocity for Case-1, $\mathrm{U}=7.304 \mathrm{~m} / \mathrm{sec}$ )

Figure 13. Comparison results of non-dimensional horizontal air velocity along the line A- $A^{\prime}$ on the plane of $y=2 \mathrm{H}$ distance from the air inlet plane at $\operatorname{Re}=5,000$ inlet flow (inlet velocity for Case-1, $U=7.304 \mathrm{~m} / \mathrm{sec}$ )

Figure 14. Comparison results of non-dimensional horizontal air velocity along the line $A^{-}-A^{\prime}$ on the plane of $y=2 \mathrm{H}$ distance from the air inlet plane at $\operatorname{Re}=7,100$ inlet flow (inlet velocity for Case-2, $U=10.371 \mathrm{~m} / \mathrm{sec}$ )

Figure 15. Gas entrainment due to turbulent diffusion in three-dimensional turbulent jet24

Figure 16. Test sections of Ricou and Spalding as modeled for the benchmarking ...... 24

Figure 17. Flow patterns along the center plane for Case-5 .................................. 25

Figure 18. Mass flow fraction of the lighter gas component $\mathrm{H}_{2}$ gas along the center plane for Case-5 ............................................................................... 26

Figure 19. Comparison of the predictions with the literature data [10] ........................ 27

Figure 20. Modeling domains for two different flow directions passing over the flow obstructions (air inlet flow $=0.2 \mathrm{~m} / \mathrm{sec}$ from the previous calculations for 150 cfm recirculation) 
Figure 21. Comparison of velocity contours between the two cases.

Figure 22. Comparison of velocity magnitude at the mid-elevation of exit plane between the flow with and without the flow obstructions

Figure 23. Modeling geometry for the internal circulation with flow obstructions under the larger domain system containing twelve 2-in pipes

Figure 24. Comparison of flow patterns between the two cases at the mid-plane for the scaled domain system.

Figure 25. Comparison of turbulent flow fluctuations between the flows with and without obstructions under $0.438 \mathrm{cfm}$ air recirculation in 174-in tank. 38

Figure 26. Comparison of velocity magnitude between the flows with and without obstructions under $0.438 \mathrm{cfm}$ air recirculation in 174-in tank 


\section{List of Tables}

Table 1. Comparison of FLUENT 6 prediction with theoretical value for the pressure drop between the planes at the two distances from the inlet $(z=3 \mathrm{~m}$ and $4 \mathrm{~m}$ in

Fig. 1)

Table 2. Comparison of maximum velocities predicted by FLUENT 6 and theoretical

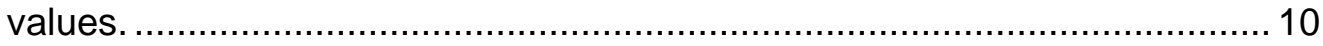

Table 3. Comparison of the results with literature data and correlations ..................... 14

Table 4. Test conditions of the literature data used for the benchmarking (The geometrical parameters are shown in Fig. 10)

Table 5. Bechmarking results of non-dimensional horizontal air velocity against the Case-1 literature data at location of $\mathrm{y}=2 \mathrm{H}$ as shown in Fig. 1

Table 6. Bechmarking results of non-dimensional horizontal air velocity against the Case-2 literature data at location of $\mathrm{y}=2 \mathrm{H}$ as shown in Fig. 1 .................... 21

Table 7. Test cases used for the modeling calculations ........................................ 24

Table 8. Bechmarking results of gas entrainments against test data [Ricou and Spalding, 1961]

Table 9. Comparison for non-uniformity of maximum local velocities for a given gas flow condition of $5.0 \times 10^{4}$ Reynolds number. .......................................... 32

Table 10. Comparison of flow obstruction impact for the scale-down flow domain........ 40 


\section{Abstract}

The FLUENT 6 CFD code has been benchmarked for a wide range of simple, classical, and complex physical problems associated with turbulent gas flow, natural convection, and turbulent mixing phenomena. The results validate the application of previous scoping calculations for the Tank 50/Tank 48 vapor space mixing.

The benchmarked problems consisted of three groups. The first group was well-defined and classical problems for which analytical solutions exist. The other groups are complex and physical problems for which analytical solutions are difficult to obtain. For these test problems, CFD results were compared and verified through comparisons with experimental results. The benchmarking of the FLUENT 6 code showed that the code predictions are in good agreement with the analytical solutions or experimental test data. The code was shown to be sufficiently accurate to make reliable decisions based on calculated results for those applications that fall within the scope of the benchmarking test cases. For applications that fall outside the range of the benchmarking results, particularly for significantly higher benzene concentrations or for flow geometries not adequately represented by the $k-\varepsilon$ turbulence model, further benchmarking work would be required. 


\section{Objective and Software Descriptions}

The FLUENT Version 6 code will be used for the dedication of computational fluid dynamics software as "Generic" applications at software Level B for engineering analysis. The code is to be tested on several classical and physical problems in the turbulent hydraulic and species transport areas. The primary objective of the present task is to verify and benchmark the modeling predictions for gas turbulent flow patterns, species diffusion transport, and the impact of flow obstructions on local flow patterns. The results will support the validation of previous scoping work for Tank 50/Tank 48 vapor space mixing [11].

The FLUENT code is a program for the prediction of laminar and turbulent flow and heat transfer, together with additional models such as multi-phase flows, combustion and species transport. The current version 6 also provides geometric capabilities by using the facility of multi-block, or block-unstructured grids; i.e., the grid may be constructed by gluing together an arbitrary number of topologically-rectangular grids, or blocks. In addition, the post-processing modules produce the main graphics output. Essentially, the code writes the numerical results to disk files, and these are read by the graphics program module.

\section{Software Installation and Computing Platform}

The FLUENT 6 code has been installed on the standard UNIX operating system by Information Technology Personnel [3]. Since the code is loaded as a binary executable file onto the IBM 6000 AIX workstations, these systems can have access to FLUENT. The test problems were performed on the following platform:

Computer platform:

Platform: $\quad$ IBM RS6000

System: $\quad$ AIX 5.1

Options: Default settings 


\section{Scope for Test problems}

The test problems were selected based on the fact that analytical solutions (or excellent approximations) exist that definitively establish the code accuracy capability and the resulting impact that mesh and control parameter settings have on accuracy. Three groups of test problems are described to validate the capability of the software to represent the physical phenomena characteristic of Savannah River Site (SRS) applications.

They are:

Group 1: Simple, well-defined, classical problems for which analytical solutions exist.

Group 2: Complex problems for which analytical solutions are difficult to obtain or don't exist. For these problems, code results are validated through comparisons with documented solutions or experimental data.

Group 3: Complex problems which are specific to the application of interest, but not necessarily required for a general validation of the code.

\subsection{Group1 Validation Problems}

\section{Turbulent isothermal flow in a pipe}

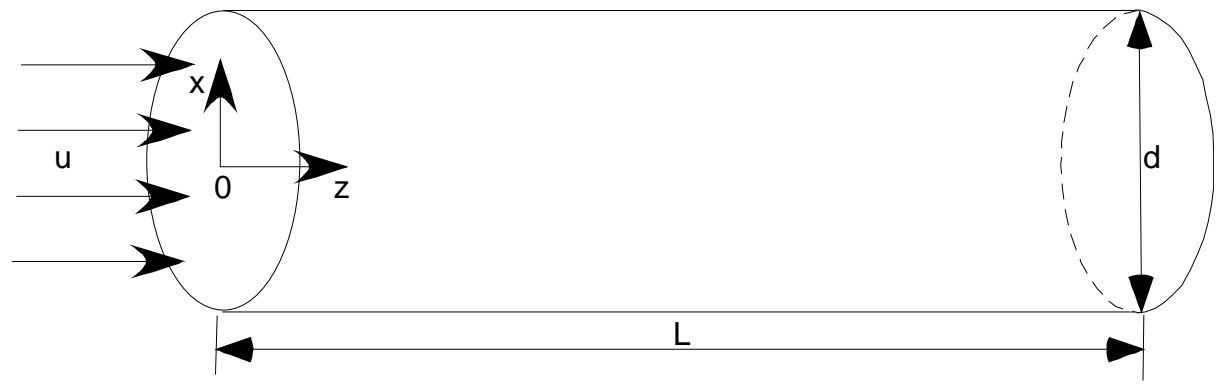

Figure 1. Isothermal flow in a circular pipe.

The main objective of this problem is to verify the prediction capabilities of the turbulent gas pressure and flow patterns in a simple geometry such as a straight pipe using the standard two-equation turbulence model (referred to as $\kappa-\varepsilon$ model) as used in the Tank 48 calculation.

When air flow in a smooth pipe is assumed to be turbulent under the isothermal flow condition, Figure 1 applies to the pipe problem for the computational modeling domain.

The parameters for the problem are as follows:

Air density $(\rho): 1.225\left(\mathrm{~kg} / \mathrm{m}^{3}\right)$

Viscosity $(\mu): \quad 1.7894 \times 10^{-5}\left(\mathrm{~N} . \mathrm{s} / \mathrm{m}^{2}\right)$

Length $(L): \quad 4.0(\mathrm{~m})$ 
$\begin{array}{ll}\text { Diameter }(d): & 0.2(\mathrm{~m}) \\ \text { Average speed }(u): & 1.710(\mathrm{~m} / \mathrm{sec})\end{array}$

Using the parameters given above, a three-dimensional steady-state flow model was developed using the standard two-equation $\kappa-\varepsilon$ turbulence model. The flow conditions inside the pipe as shown in Fig. 1 were assumed to be turbulent since the Reynolds number was about 23,000 in terms of inlet flow conditions. The calculated flow patterns are shown in Fig. 2. As shown in Fig. 3, the calculated results show that the inlet flow was fully developed within about 15 pipe diameters $(L / d=15)$. The results are consistent with literature data [6].

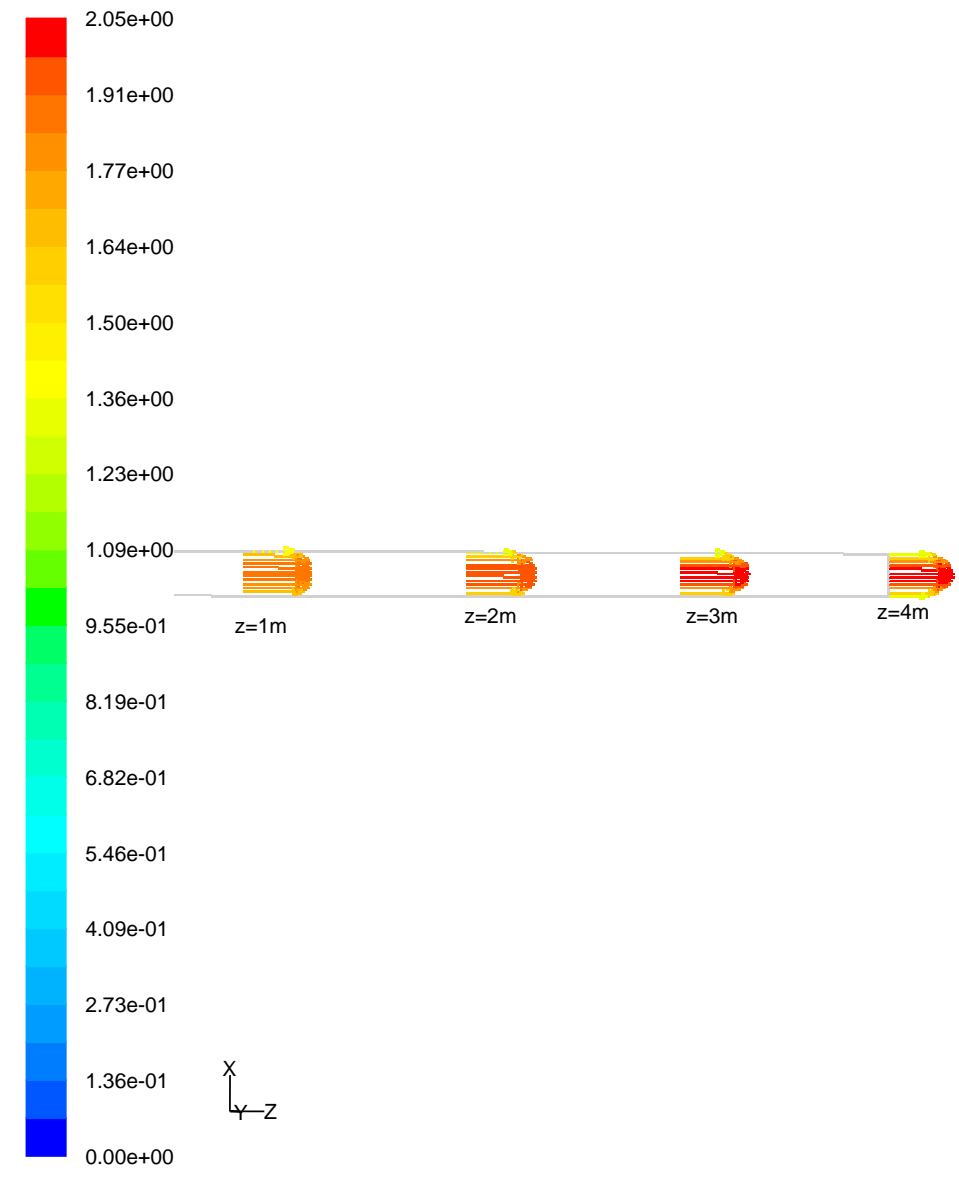

Velocity Vectors Colored By Velocity Magnitude $(\mathrm{m} / \mathrm{s})$

Nov 28, 2005

FLUENT 6.2 (3d, segregated, ske)

Figure 2. Flow patterns at various distances from the air entrance in 0.2-m pipe 


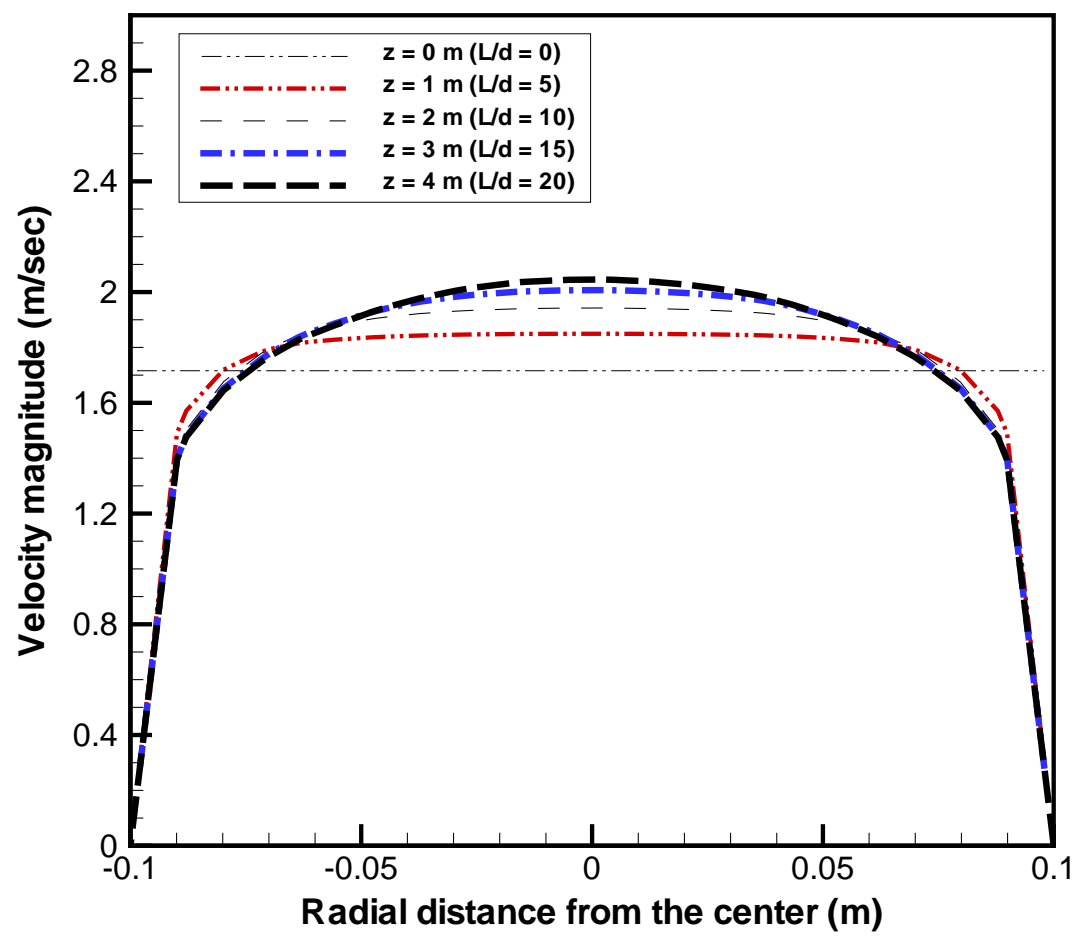

Figure 3. Radial velocity distributions for various distances from the entrance demonstrating that flow is fully developed at about 15 diameters from the pipe inlet, consistent with literature information [6].

The pressure drop $(\Delta P)$ expected for this section of flow in this pipe geometry can be found from the expression,

$$
\begin{aligned}
\Delta P & =P_{x=3 m}-P_{x=4 m} \\
& =\frac{1}{2} \rho u^{2}\left(f \frac{L}{d}\right)
\end{aligned}
$$

In Equation (1), $f=0.0256$ for a smooth pipe from the Moody's chart (or $f=0.0791 / \mathrm{Re}^{0.25}$ ) in the literature [5] for a flow condition corresponding to $\mathrm{Re}=2.341 \times 10^{4}$. From Eq. (1), the pressure drop across the distance between 3 and $4 \mathrm{~m}$ from the entrance is $0.229 \mathrm{~Pa}$ for a turbulent smooth pipe.

FLUENT 6 predicted $\Delta \mathrm{P}=0.217 \mathrm{~Pa}$ for the circular pipe problem as shown in Table 1. 
Table 1. Comparison of FLUENT 6 prediction with theoretical value for the pressure drop between the planes at the two distances from the inlet $(z=3 \mathrm{~m}$ and $4 \mathrm{~m}$ in Fig.

1).

\begin{tabular}{|c|c|c|c|}
\hline \multirow{2}{*}{ Prob. 1 } & $\begin{array}{c}\text { Theoretical Value } \\
(\mathrm{Pa})\end{array}$ & $\begin{array}{c}\text { FLUENT 6 } \\
\text { Prediction } \\
(\mathrm{Pa})\end{array}$ & $\begin{array}{c}\text { Relative Error } \\
(\%)\end{array}$ \\
\cline { 2 - 4 } & 0.229 & 0.217 & 5.24 \\
\hline
\end{tabular}

Two-dimensional natural convection inside a rectangular enclosure with specified boundary temperatures

The two-dimensional natural convection problem with specified boundary temperatures consists of a rectangular enclosure with adiabatic horizontal walls and isothermal vertical walls maintained at a fixed temperature difference. The temperature differences between the hot and cold walls are $10 \mathrm{~K}$ for the first case and $25 \mathrm{~K}$ for the second case. The model calculation is based on conduction and natural convection of heat through the gas medium. The height and width of the enclosure were arbitrarily chosen to be $0.5 \mathrm{~m}$ and $0.0254 \mathrm{~m}$ respectively, which is an aspect ratio of about 20 and generally considered a narrow slit geometry. A schematic of this problem is shown in Fig. 4. 


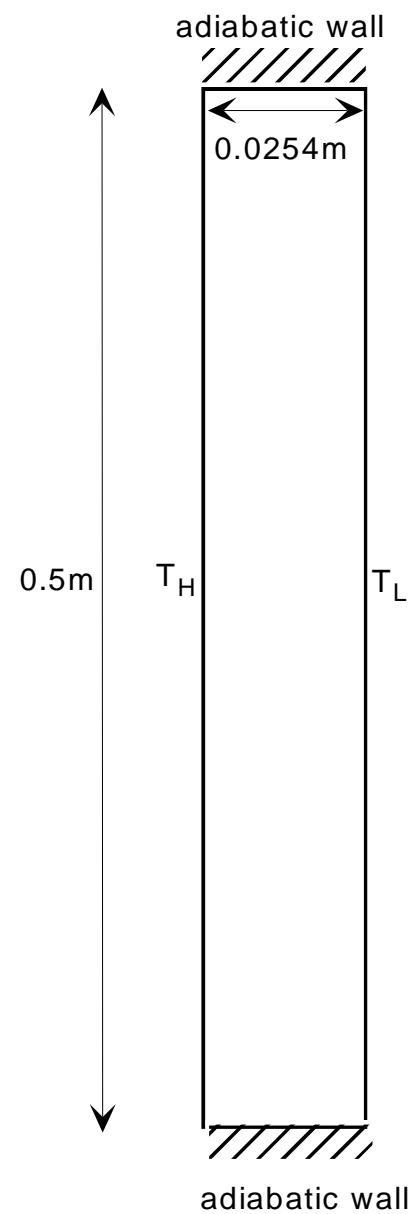

Figure 4. Natural convection inside a slit enclosure.

An analytical solution for the natural convection problem can be determined for an idealized representation of the problem as fully developed flow between two infinite parallel plates as shown in Fig. 5. The momentum and energy equations for this twodimensional problem can be expressed in the following form:

$g \beta\left(T-T_{m}\right)+\left(\frac{\mu}{\rho}\right)\left(\frac{\partial^{2} u}{\partial x^{2}}\right)=0$

$\left(\frac{\partial^{2} T}{\partial x^{2}}\right)=0$

where $u$ is the $y$-direction component of the velocity and the Boussinesq approximation has been applied to the gravitational term of Eq. (2). The reference temperature for the problem is taken as 
$T_{m}=\frac{1}{2}\left(T_{H}-T_{L}\right)$

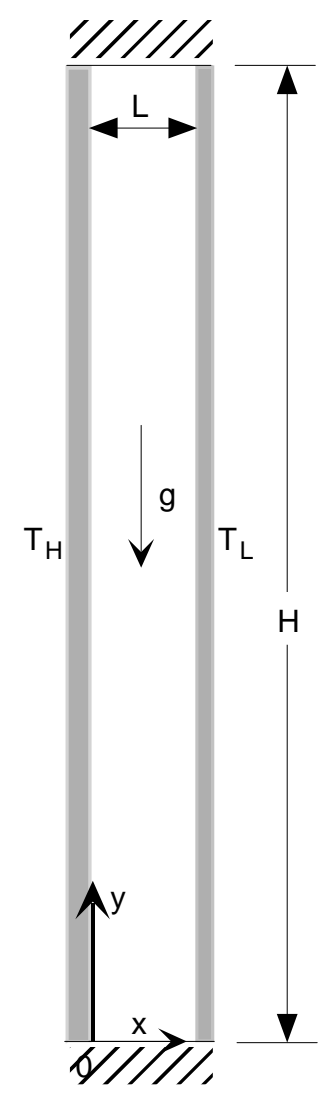

Figure 5. Geometry for natural convection model.

With the boundary conditions

$T=T_{H}$ at $\mathrm{x}=0$ and $T=T_{L}$ at $\mathrm{x}=\mathrm{L}$,

the energy equation can be solved to give

$T(x)=T_{H}-\left(T_{H}-T_{L}\right)\left(\frac{x}{L}\right)$

Substituing eq. (4) and (5) into Eq. (2) results in

$\frac{d^{2} u(x)}{d x^{2}}=\left(\frac{g \beta \rho}{\mu}\right)\left(T_{H}-T_{m}\right)\left(2 \frac{x}{L}-1\right)$

Integrating once gives 
$\frac{d u(x)}{d x}=\left(\frac{g \beta \rho}{\mu}\right)\left(T_{H}-T_{m}\right)\left(\frac{x^{2}}{L}-x\right)+A$

Integrating a second time gives

$u(x)=\left(\frac{g \beta \rho}{\mu}\right)\left(T_{H}-T_{m}\right)\left(\frac{x^{3}}{3 L}-\frac{x^{2}}{2}\right)+A x+B$

Using no-slip boundary condition $(u(x)=0)$ at $x=0$ and $x=\mathrm{L}$ allows the constants $A$ and $B$ of eqs. (7) and (8) to be determined.

$A=\frac{g \beta \rho}{6 \mu} L\left(T_{H}-T_{m}\right)$

$B=0$

Substituting the constants of Eq. (9) into Eq. (8) results in the following expression for $u(x)$ :

$u(x)=\left(\frac{g \beta \rho}{12 \mu}\right) L^{2}\left(T_{H}-T_{L}\right)\left\{2\left(\frac{x}{L}\right)^{3}-3\left(\frac{x}{L}\right)^{2}+\left(\frac{x}{L}\right)\right\}$

This expression shows extrema at $x / L=0.211$ and 0.789 . The magnitude of the term in brackets at the extrema is \pm 0.0962 . This value can be multiplied by the physical constants in Eq. (10) and compared to numerical results. The physical constants are

$$
\begin{aligned}
& \rho=0.1626 \mathrm{~kg} / \mathrm{m}^{3} \\
& \beta=2.85 \times 10^{-3} \mathrm{~K}^{-1} \\
& g=9.81 \mathrm{~m} / \mathrm{sec}^{2} \\
& \mu=2.0 \times 10^{-5} \mathrm{~N}-\mathrm{sec} / \mathrm{m}^{2} \\
& L=0.0254 \mathrm{~m}
\end{aligned}
$$

With these values, the maximum velocity at the mid-plane of the rectangular enclosure is theoretically

Case 1: $u= \pm 0.01176 \mathrm{~m} / \mathrm{sec}$ for $\Delta T=\left(T_{H}-T_{L}\right)=10 \mathrm{~K}$

Case 2: $u= \pm 0.02939 \mathrm{~m} / \mathrm{sec}$ for $\Delta T=\left(T_{H}-T_{L}\right)=25 \mathrm{~K}$

The profile of velocity across the width of the gap is as important as the maximum value within the gap of the slit geometry. Figure 6 and Figure 7 show the profile comparison for these two cases. Table 2 also shows comparison of the peak values predicted by FLUENT 6 with the theoretical ones. 
Page: $\quad 10$ of 42

Table 2. Comparison of maximum velocities predicted by FLUENT 6 and theoretical values.

\begin{tabular}{|c|c|c|c|}
\hline Cases & $\begin{array}{c}\text { Theoretical Values } \\
(\mathrm{m} / \mathrm{sec})\end{array}$ & $\begin{array}{c}\text { FLUENT 6 } \\
\text { Prediction } \\
(\mathrm{m} / \mathrm{sec})\end{array}$ & $\begin{array}{c}\text { Relative Error } \\
(\%)\end{array}$ \\
\hline Case 1 & 0.01176 & 0.01129 & 2.84 \\
\hline Case 2 & 0.02939 & 0.02822 & 2.96 \\
\hline
\end{tabular}

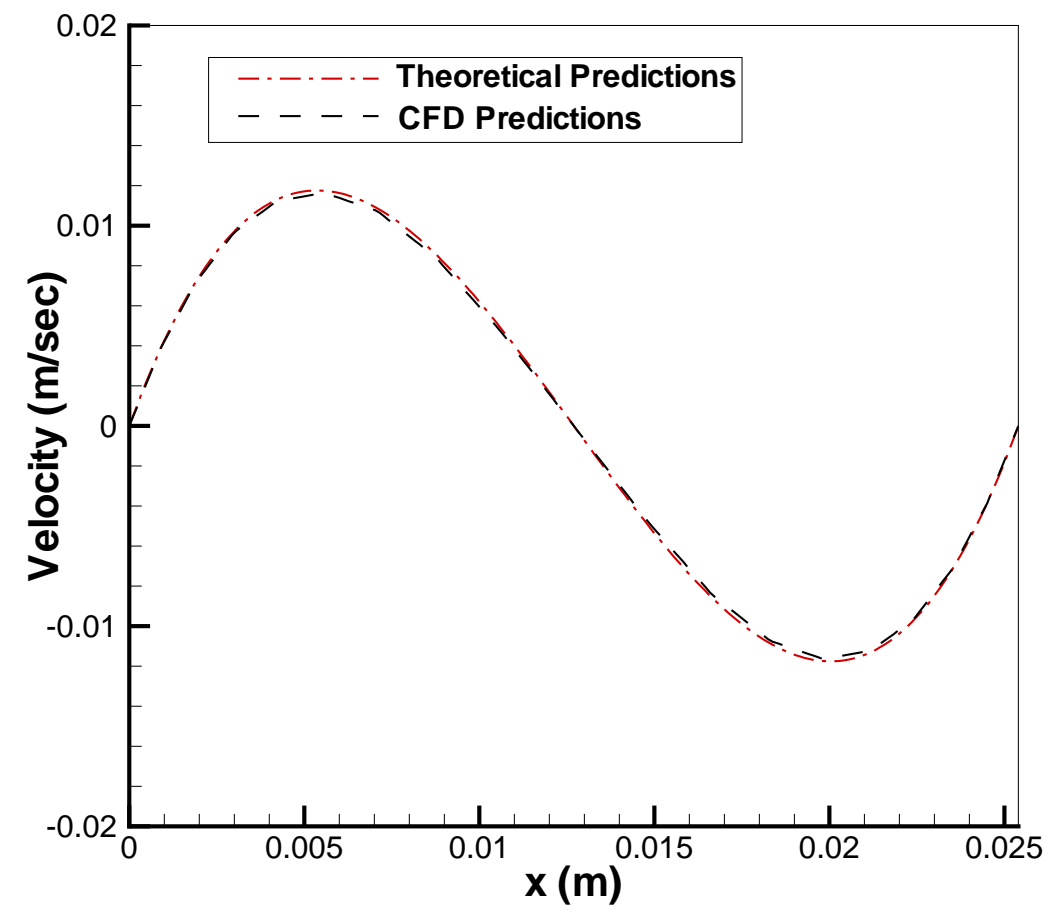

Figure 6. Comparison of FLUENT6 predictions with theoretical predictions for Case1 


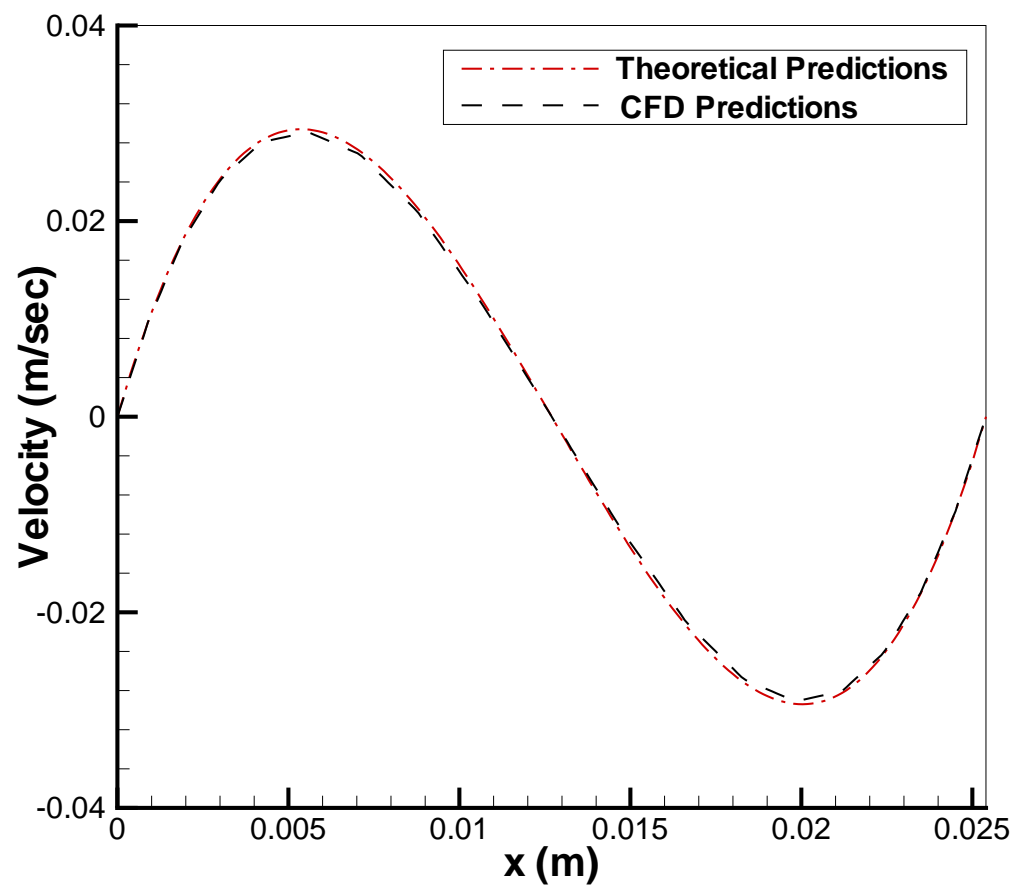

Figure 7. Comparison of FLUENT6 predictions with theoretical predictions for Case2 


\subsection{Group2 Validation Problems}

\section{$\underline{k-\varepsilon \text { model evaluation for three-dimensional turbulent free jet }}$}

The turbulent jet problem assesses the capability of the computational flow model to address turbulent flow dissipation phenomena. In the present benchmarking test, axial momentum dissipation is assessed against data since the axial velocity drives the liquid mixing inside the container. The overall behavior of the calculated axial velocity distribution was in good agreement with both data and theory, and comparisons against a correlation of turbulent jet axial velocity showed nearly perfect agreement between the FLUENT 6 predictions and the published correlations. The computed FLUENT 6 results were based on the typical turbulence model in the literature, the $k-\varepsilon$ turbulence model, sometimes referred to as a two-equation model.

A model of a turbulent jet in water with a nozzle diameter of $9.525 \times 10^{-3} \mathrm{~m}$ and an inlet velocity of $12 \mathrm{ft} / \mathrm{sec}$, corresponding to Reynolds number of 35,500, is used. The jet discharges perpendicular to the bounding wall of a box $2 \mathrm{ft}$ on a side and $4 \mathrm{ft}$ long. Detailed geometrical dimensions are shown in Fig. 8.

Considering the nature of turbulence modeling, comparisons of the predictions with the literature data are achieved with reasonable accuracy. Detailed comparisons of the predictions with the literature data (Kiser) are made in Table 3. However, the FLUENT 6 predictions are also in reasonably good agreement with the literature correlations (Rushton, Abramovich) as shown in Fig. 9. Comparisons between the code and data must address the qualitative behavior of the code results as well as the quantitative behavior. Comparisons in the developing region of the flow should not be considered as important as results in the fully developed region. The expected $1 / z$ behavior of the axial velocity should be observed over the developed region of the jet, even if the numerical comparisons of velocity at a given location are not quite within $10 \%$. The comparison was made by translating the non-dimensional axial velocity distribution to achieve the best possible comparison with the theoretical $1 / z$ behavior along the axial flow direction. Results and analysis from both data and the literature are also found in Reference 7. Because the non-dimensional behavior of air and water jets are similar [13], both types of data have been used for this comparison. 


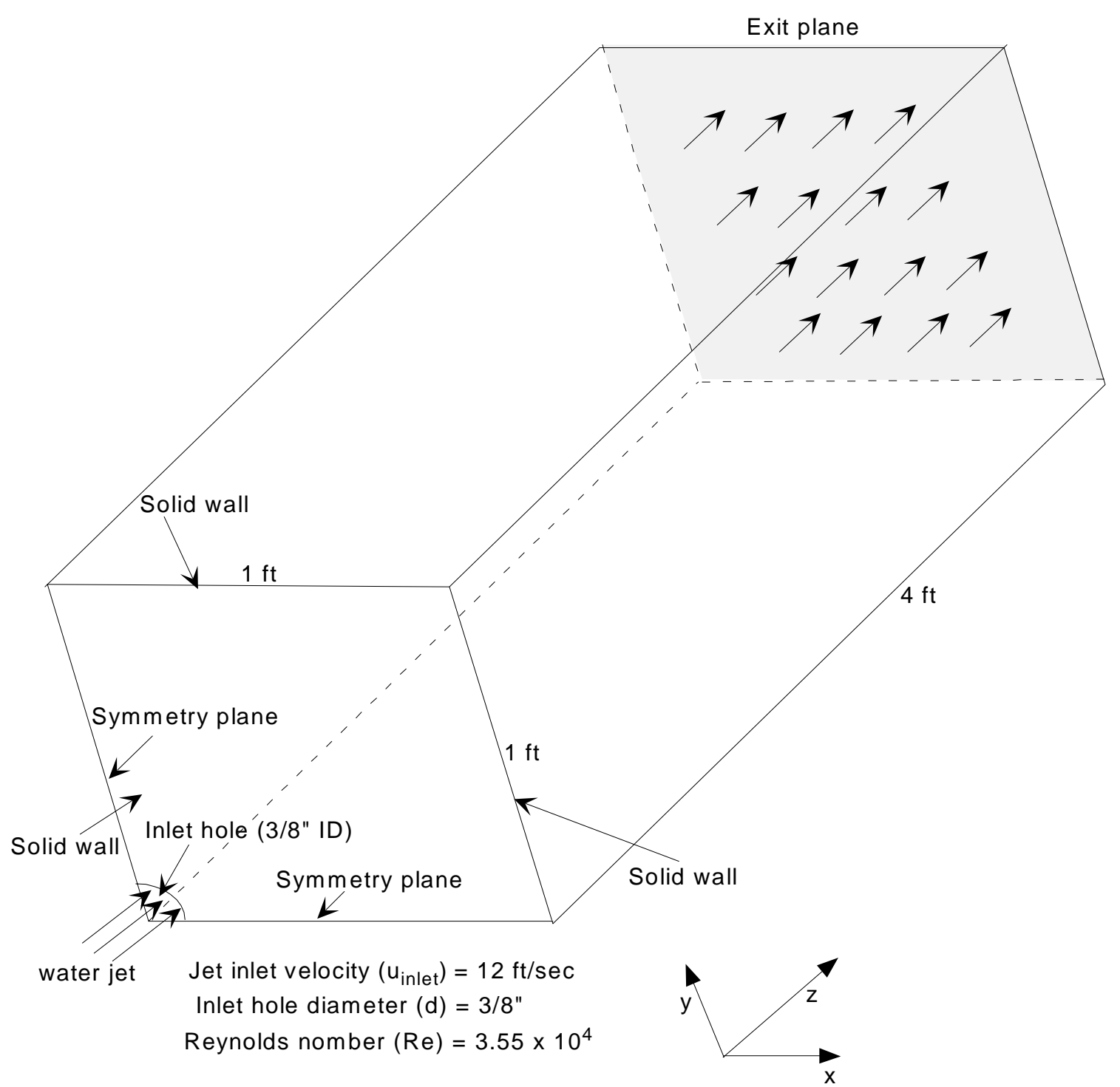

Figure 8. Schematic diagram of the water jet system conducted by Kiser (1963) and CFD three-dimensional modeling and computational domain with two symmetrical planes. 
Page: $\quad 14$ of 42

Table 3. Comparison of the results with literature data and correlations

\begin{tabular}{|c|c|c|c|c|c|}
\hline \multirow{2}{*}{$\begin{array}{l}\text { Position } \\
\text { along the } \\
\text { axial z- } \\
\text { direction } \\
\text { (x/d) }\end{array}$} & \multirow{2}{*}{$\begin{array}{l}\text { CFD } \\
\text { predictions } \\
\left(v / u_{\text {inlet }}\right)\end{array}$} & \multicolumn{4}{|c|}{$\begin{array}{l}\text { Literature data/correlations for non-dimensional velocity w.r.t } \\
\text { inlet velocity }\left(v / u_{\text {inlet }}\right)\end{array}$} \\
\hline & & $\begin{array}{c}\text { Kiser data } \\
\text { (1963) }\end{array}$ & $\begin{array}{l}\text { Rushton }^{1} \\
\quad(1980)\end{array}$ & $\begin{array}{l}\text { Abramovich } \\
\quad(1963)\end{array}$ & $\begin{array}{l}\text { Relative \% difference } \\
\text { between CFD } \\
\text { predictions and Kise } \\
\text { data (1963) }\end{array}$ \\
\hline 7.0 & 0.7479 & --- & 0.8295 & 0.9031 & --- \\
\hline 9.30 & 0.5850 & 0.570 & 0.6245 & 0.6799 & 2.63 \\
\hline 14.6 & 0.3733 & 0.365 & 0.3975 & 0.4328 & 2.27 \\
\hline 20.0 & 0.2706 & 0.260 & 0.2901 & 0.3158 & 4.08 \\
\hline 26.0 & 0.2075 & 0.190 & 0.2232 & 0.2430 & 9.21 \\
\hline 32.0 & 0.1572 & 0.141 & 0.1813 & 0.1974 & 11.5 \\
\hline 40.0 & 0.1349 & 0.125 & 0.1450 & 0.1579 & 7.92 \\
\hline
\end{tabular}

Note: Literature correlations

1. Rushton (1980) correlation (valid for $(z / d)>6)$ :

$$
\frac{v}{u_{\text {inlet }}}=1.410 \mathrm{Re}^{0.135}\left(\frac{z}{d}\right)^{-1}
$$

2. Abramovich (1963) correlation (valid for $(z / d)>6$ ):

$$
\frac{v}{u_{\text {inlet }}}=6.3158\left(\frac{z}{d}\right)^{-1}
$$




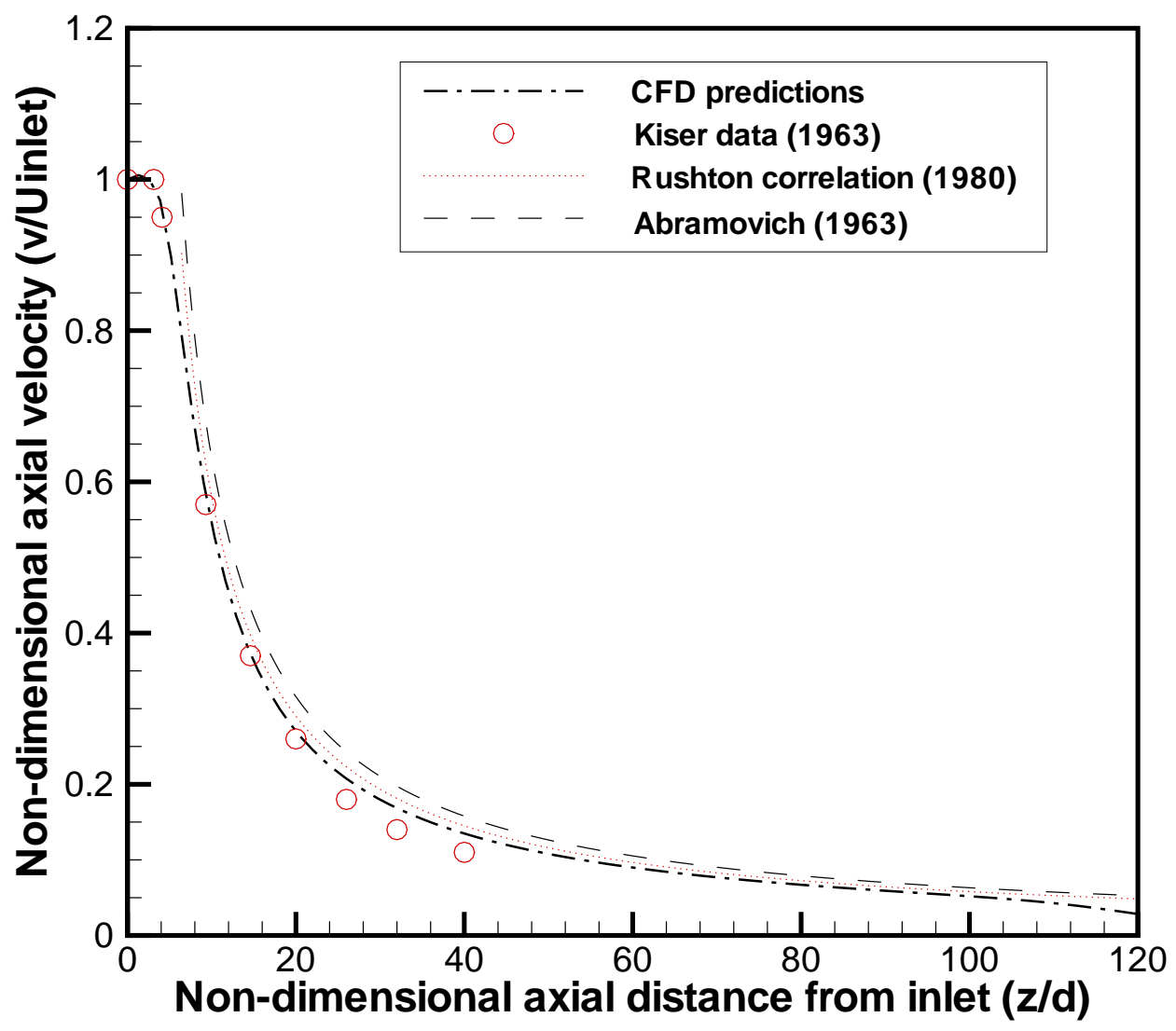

Figure 9. Comparison of the turbulent jet axial velocity predicted by the CFD code with the test data and the published correlations available in the literature. 


\section{$\underline{k-\varepsilon}$ turbulence model evaluation in a three-dimensional ventilated room}

Turbulent air flow characteristics of a ventilated room were experimentally investigated by Nielsen et al. [8]. The geometrical arrangements used for their experiments are represented by Fig. 10. The figure also indicates the coordinate system and geometrical parameters. The air flow measurements were obtained at Reynolds numbers from 5,000 to 10,000. The current benchmarks of the CFD model against the test data used two test conditions as provided by Table 4.

The air ventilation problem assesses the capability of the $k-\varepsilon$ model in the Fluent code to address turbulent flow phenomena such as flow recirculation inside the ventilated room. In the present benchmarking test, air flow patterns such as recirculation are assessed against the data for two different Reynolds numbers, 5000 and 7100, since the inlet air velocity drives the gas motion inside the ventilated room. The overall behaviors of the calculated mean velocity distributions were in good agreement with the test data, and quantitative comparisons against the data showed reasonably good agreement between the FLUENT 6 predictions and the published data. The computed FLUENT 6 results were based on the standard $k-\varepsilon$ turbulence model.

One of the two cases in Table 4 is modeled for a turbulent air into a room through a slit of $5 \times 10^{-3} \mathrm{~m}$ and an inlet velocity of about $7.304 \mathrm{~m} / \mathrm{sec}(24 \mathrm{ft} / \mathrm{sec})$, corresponding to a Reynolds number of 5,000 . The other case has inlet velocity of $10.371 \mathrm{~m} / \mathrm{sec}(34 \mathrm{ft} / \mathrm{sec})$ corresponding to a Reynolds number of 7,100. The air comes horizontally into the bounding wall of a rectangular room of length $L$, width $W$, and height $H$. Both cases have different combinations of non-dimensional ratios for the rectangular room with $H=$ $0.0893 \mathrm{~m}$. Detailed geometrical dimensions are shown in Fig. 10.

A three-dimensional turbulent model was constructed with Fluent using the standard $k-\varepsilon$ model to simulate air flow in a ventilated room. A steady state approach was taken to calculate the air flow patterns inside the room. The modeling conditions were provided in Table 4. The calculations were performed with approximately 250,000 grid nodes and required about 6 hours of computing time on an IBM RS6000. The calculated flow patterns at the center plane for Case-1 are shown in Fig. 11. Maximum local velocity along the bulk flow direction agrees with the literature data within about 15\% as shown in Fig. 12. Figure 13 shows comparison results for the non-dimensional horizontal air velocity along the line A-A' of Fig. 10 at a distance $y=2 H$ from the air inlet plane of Case1. The quantitative comparison shows that the predicted results are in agreement with the test results within about 18\%. The detailed results are summarized in Table 5. The modeling results for the higher Reynolds number of Case-2 are presented in Fig. 14. The benchmarking results for this case show that the calculated results agree with the test results within about $10 \%$ as shown in Table 6 . The results demonstrate that the $k-\varepsilon$ turbulence model can accurately predict the flow patterns for ventilation air flow in a room within about $18 \%$ relative error. 


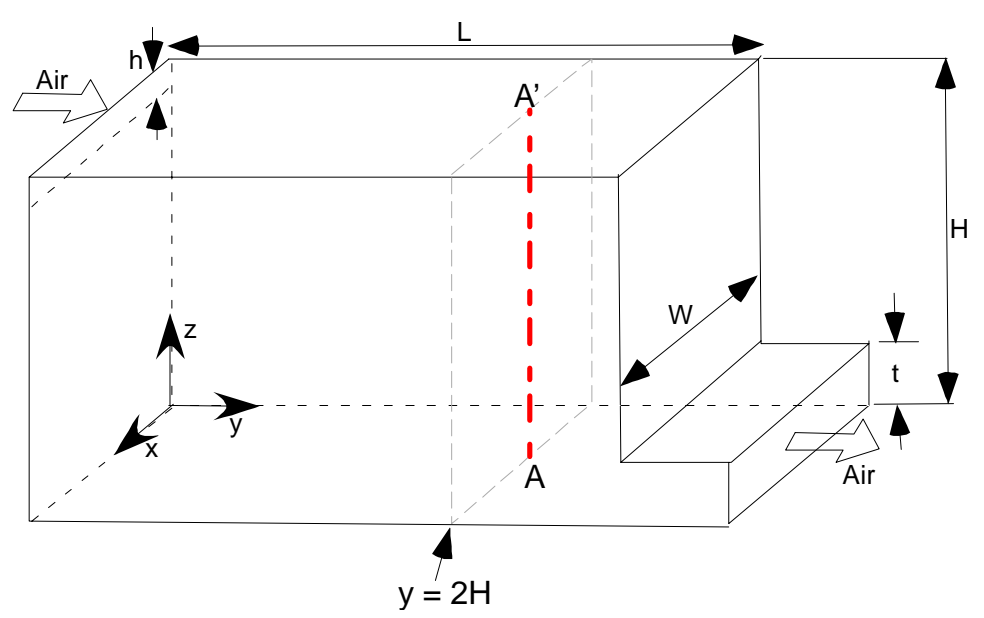

(Case-1: $\mathrm{L} / \mathrm{H}=3.0, \mathrm{~W} / \mathrm{H}=1.0, \mathrm{~h} / \mathrm{H}=0.056, \mathrm{t} / \mathrm{H}=0.16, \mathrm{H}=0.0893 \mathrm{~m}$ )

(Case-2: $\mathrm{L} / \mathrm{H}=3.1, \mathrm{~W} / \mathrm{H}=4.7, \mathrm{~h} / \mathrm{H}=0.056, \mathrm{t} / \mathrm{H}=0.16, \mathrm{H}=0.0893 \mathrm{~m}$ )

Figure 10. Geometric arrangements and modeling coordinate system of the ventilated room used by Nielsen et al. $[8,16]$

Table 4. Test conditions of the literature data used for the benchmarking (The geometrical parameters are shown in Fig. 10)

\begin{tabular}{|c|c|c|c|c|c|c|}
\hline \multicolumn{2}{|c|}{} & \multicolumn{3}{c|}{$\mathrm{H}=0.0893 \mathrm{~m}$} & \multirow{2}{*}{$\begin{array}{c}\text { Re } \\
\text { (inlet velocity) }\end{array}$} \\
\cline { 3 - 6 } & $\mathrm{L} / \mathrm{H}$ & $\mathrm{h} / \mathrm{H}$ & $\mathrm{W} / \mathrm{H}$ & $\mathrm{w} / \mathrm{W}$ & \\
\hline Case-1 & $\begin{array}{c}\text { Nielsen et al. } \\
{[8]}\end{array}$ & 3.0 & 0.056 & 1 & 1.0 & $\begin{array}{c}5,000 \\
(7.304 \mathrm{~m} / \mathrm{sec})\end{array}$ \\
\hline Case-2 & Nielsen [16] & 3.1 & 0.056 & 4.7 & 1.0 & $\begin{array}{c}7,100 \\
(10.371 \mathrm{~m} / \mathrm{sec})\end{array}$ \\
\hline
\end{tabular}


Page: $\quad 18$ of 42

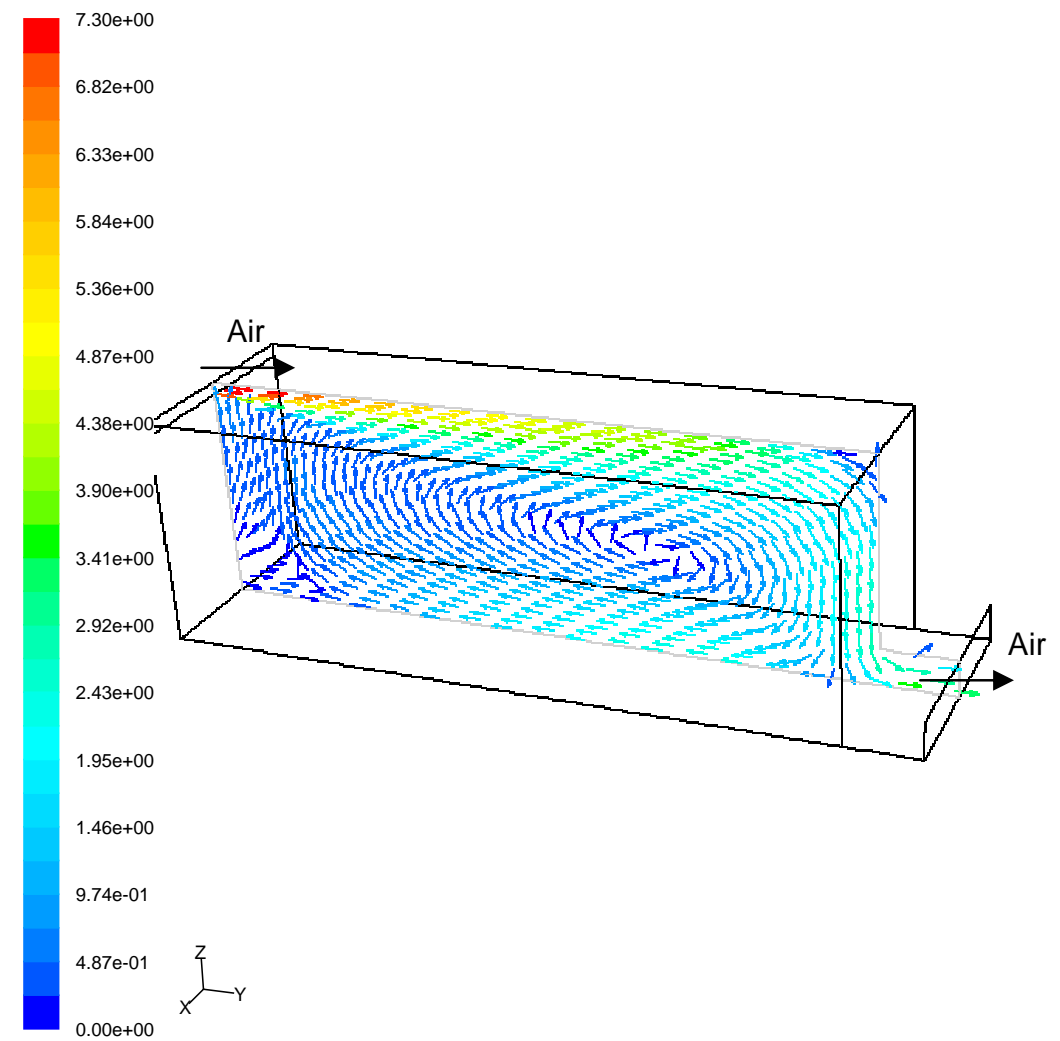

Velocity Vectors Colored By Velocity Magnitude $(\mathrm{m} / \mathrm{s})$

Nov 22, 2005

FLUENT 6.2 (3d, segregated, ske)

Figure 11. Flow patterns at the middle plane of the Case-1 ventilated room conducted by Nielsen et al. [8] 


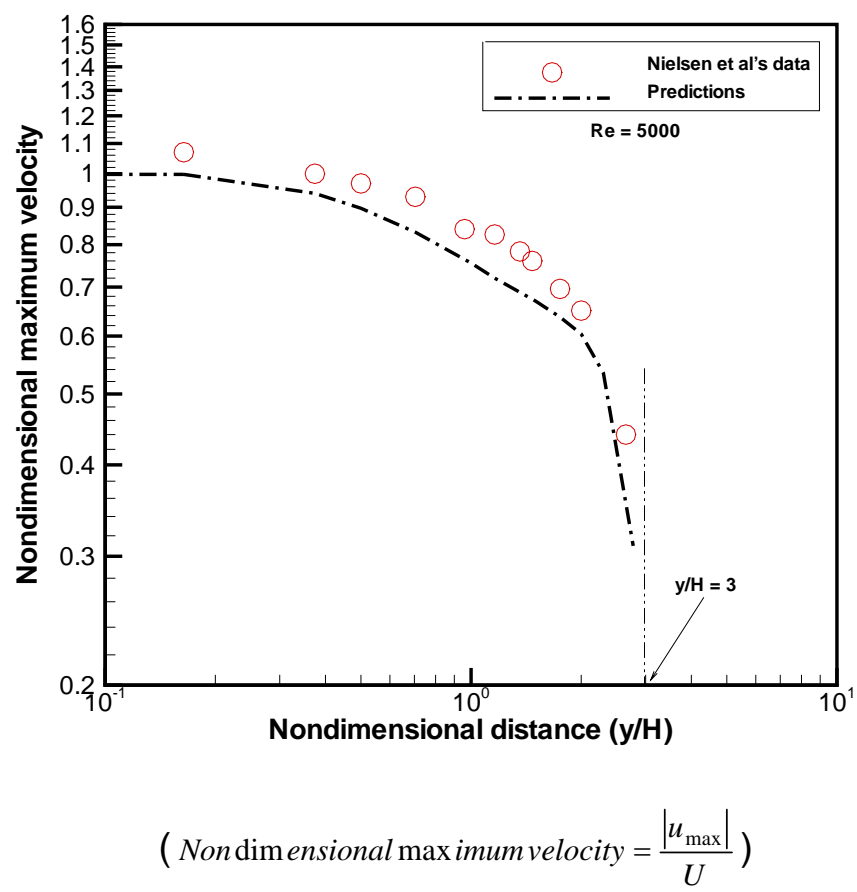

Figure 12. Comparison results of non-dimensional maximum velocity magnitude along the incoming flow direction from the air inlet plane at $\mathrm{Re}=5,000$ inlet flow (inlet velocity for Case-1, $U=7.304 \mathrm{~m} / \mathrm{sec}$ )

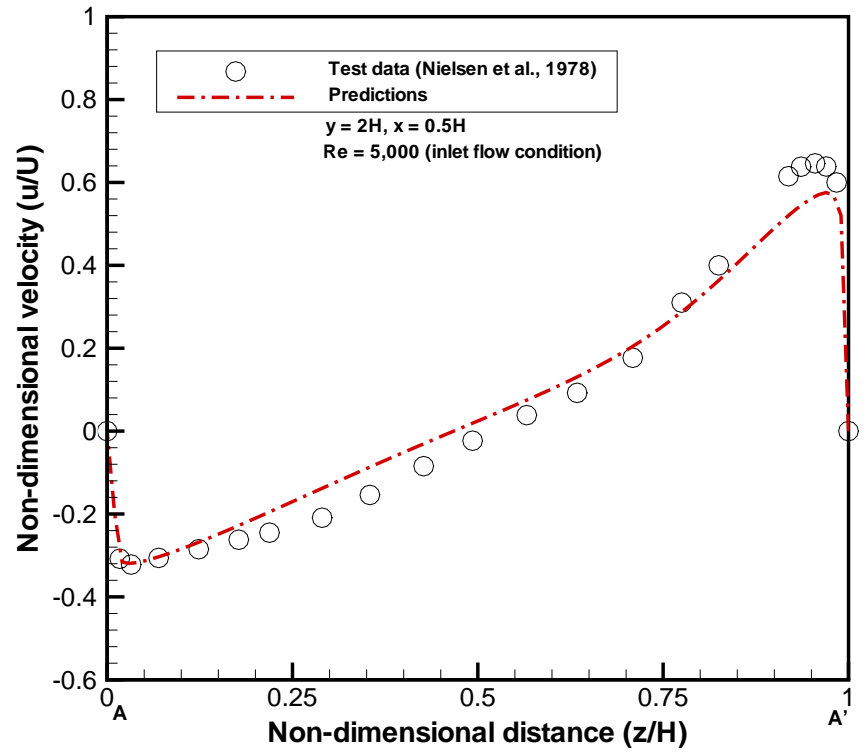

Figure 13. Comparison results of non-dimensional horizontal air velocity along the line A-A' on the plane of $y=2 \mathrm{H}$ distance from the air inlet plane at $\mathrm{Re}=5,000$ inlet flow (inlet velocity for Case- $1, U=7.304 \mathrm{~m} / \mathrm{sec}$ ) 
Page: $\quad 20$ of 42

Table 5. Bechmarking results of non-dimensional horizontal air velocity against the Case-1 literature data at location of $\mathrm{y}=2 \mathrm{H}$ as shown in Fig. 1

\begin{tabular}{|c|c|c|c|c|}
\hline $\begin{array}{c}\text { Inlet velocity, } \mathbf{U} \\
\text { (Reynolds } \\
\text { number, Re*) }\end{array}$ & $\begin{array}{c}\text { Non-dimensional } \\
\text { vertical distance } \\
\text { at } \mathbf{y}=\mathbf{2 H}(\mathbf{z} / \mathbf{H})\end{array}$ & $\begin{array}{c}\text { Test data } \\
\mathbf{( u / U )}\end{array}$ & $\begin{array}{c}\text { Predictions } \\
\mathbf{( u / U )}\end{array}$ & $\begin{array}{c}\text { Relative error } \\
\mathbf{( \% )}\end{array}$ \\
\hline \multirow{3}{*}{$\mathrm{U}=7.304 \mathrm{~m} / \mathrm{sec}$} & 0.0170 & -0.308 & -0.279 & 9.42 \\
\cline { 2 - 5 } & 0.0324 & -0.322 & -0.319 & 0.93 \\
\cline { 2 - 5 }$\left(5.0 \times 10^{3}\right)$ & 0.178 & -0.262 & -0.228 & 13.0 \\
\cline { 2 - 5 } & 0.219 & -0.245 & -0.200 & 18.4 \\
\cline { 2 - 5 } & 0.709 & 0.177 & 0.204 & 15.0 \\
\cline { 2 - 5 } & 0.825 & 0.400 & 0.364 & 9.0 \\
\cline { 2 - 5 } & 0.955 & 0.646 & 0.566 & 12.4 \\
\hline
\end{tabular}

Note: * $\operatorname{Re}=\left(d_{h} \rho U / \mu\right)$

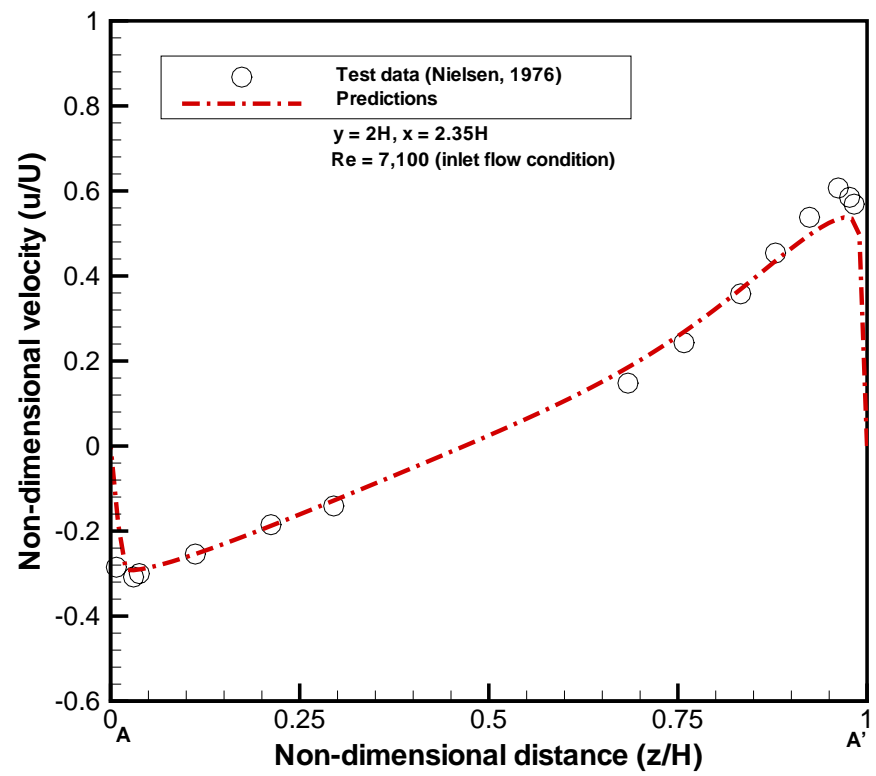

Figure 14. Comparison results of non-dimensional horizontal air velocity along the line A-A' on the plane of $y=2 \mathrm{H}$ distance from the air inlet plane at $\operatorname{Re}=7,100$ inlet flow (inlet velocity for Case-2, $U=10.371 \mathrm{~m} / \mathrm{sec}$ ) 
Table 6. Bechmarking results of non-dimensional horizontal air velocity against the Case-2 literature data at location of $\mathrm{y}=2 \mathrm{H}$ as shown in Fig. 1

\begin{tabular}{|c|c|c|c|c|}
\hline $\begin{array}{c}\text { Inlet velocity, } \mathbf{U} \\
\text { (Reynolds } \\
\text { number, Re* }\end{array}$ & $\begin{array}{c}\text { Non-dimensional } \\
\text { vertical distance } \\
\text { at } \mathbf{y}=\mathbf{2 H}(\mathbf{z} / \mathbf{H})\end{array}$ & $\begin{array}{c}\text { Test data } \\
\mathbf{( u / U )}\end{array}$ & $\begin{array}{c}\text { Predictions } \\
\mathbf{( u / U )}\end{array}$ & $\begin{array}{c}\text { Relative error } \\
\mathbf{( \% )}\end{array}$ \\
\hline \multirow{4}{*}{$\mathrm{U}=10.371 \mathrm{~m} / \mathrm{sec}$} & 0.0303 & -0.308 & -0.292 & 5.19 \\
\cline { 2 - 5 } & 0.112 & -0.254 & -0.254 & 0.0 \\
\cline { 2 - 5 }$\left(7.1 \times 10^{3}\right)$ & 0.212 & -0.185 & -0.188 & 1.62 \\
\cline { 2 - 5 } & 0.295 & -0.141 & 0.129 & 8.51 \\
\cline { 2 - 5 } & 0.758 & 0.243 & 0.267 & 9.88 \\
\cline { 2 - 5 } & 0.833 & 0.358 & 0.367 & 2.51 \\
\cline { 2 - 5 } & 0.962 & 0.607 & 0.532 & 12.4 \\
\cline { 2 - 5 } & 0.983 & 0.569 & 0.521 & 8.44 \\
\hline
\end{tabular}

Note: ${ }^{*} \operatorname{Re}=\left(d_{h} \rho U / \mu\right)$

\section{Turbulent mixing evaluation in a three-dimensional axisymmetric jet}

The present validation work is focused on both momentum and mass diffusion under turbulent flow conditions. The literature data and information [12] clearly show that the turbulent Prandtl number $(v / \alpha)$ and the Schmidt number ( $v / D)$ are within about $10 \%$ of 0.70 , independent of the nature of the experiment and the magnitude of flow and concentration conditions. The Prandtl number is the ratio of the momentum exchange coefficient $(v)$ to the temperature exchange coefficient $(\alpha)$. Likewise, the ratio of momentum exchange coefficient $(v)$ to mass exchange coefficient $(D)$ is known as the Schmidt number. The literature results show that the normalized velocity and concentration profiles are identical within the accuracy of the measurements. Therefore, the turbulent mixing calculations for this evaluation use Schmidt numbers of 0.7.

An example for a turbulent gas mixing layer is illustrated diagrammatically in Fig. 15. It is assumed that a uniform irrotational stream emerges from a nozzle into a region where the surrounding fluid is at rest at atmospheric pressure. A sheet of vorticity will be generated at the interface between the moving fluid and the stationary fluid and this leads to the formation of a wedge-shaped turbulent mixing layer. It is observed experimentally that the turbulent mixing layer spreads outwards at a relatively small angle, about $14^{\circ}$, as indicated in the diagram, although it should be noted that the edges of the turbulent zone are intermittent in character like the outer edge of a turbulent boundary layer [12]. When the turbulent boundary layer equation is applied to the 
mixing layer along the $x$-direction of the primary gas flow as shown in Fig. 15, and the pressure gradient in the $x$-direction is assumed to be zero, the steady-state momentum conservation equation for the boundary mixing region in the $x$-direction is given as

$$
\rho\left(\overline{u_{x}} \frac{\partial \overline{u_{x}}}{\partial x}+\overline{u_{y}} \frac{\partial \overline{u_{x}}}{\partial y}\right) \approx-\rho\left(\frac{\partial\left(\overline{u_{x}^{\prime} u_{y}^{\prime}}\right)}{\partial y}\right)
$$

Following the literature approach [6] regarding the Reynolds stress term on the righthand side of Eq. (13), it is reasonably assumed that the kinematic eddy viscosity $v_{\text {eff }}$ should be constant with respect to $y$ over the cross-section of the mixing layer. Using this assumption and the basic hypothesis of the turbulent mixing length, $\ell$, the right-hand side term of the equation can be given in terms of the kinematic eddy viscosity $v_{\text {eff }}$, that is,

$$
\left(\overline{u_{x}^{\prime} u_{y}^{\prime}}\right)=-\ell^{2}\left|\frac{\partial \overline{u_{x}}}{\partial y}\right|\left(\frac{\partial \overline{u_{x}}}{\partial y}\right)=-v_{\text {eff }}\left(\frac{\partial \overline{u_{x}}}{\partial y}\right)
$$

In Eq. (14) turbulent diffusivity is described by the center-line velocity $U$ at distance $x$.

$$
v_{\text {eff }}=C_{v} U x
$$

From Eqs. (13) and (14), the resulting equation becomes

$$
\left(\overline{u_{x}} \frac{\partial \overline{u_{x}}}{\partial x}+\overline{u_{y}} \frac{\partial \overline{u_{x}}}{\partial y}\right) \approx v_{e f f}\left(\frac{\partial^{2} \overline{u_{x}}}{\partial^{2} y}\right)
$$

From Eq. (16), the flow momentum driven by the gas jet is dissipated by turbulent eddy diffusivity, $v_{\text {eff, }}$ leading to the entrainment of the stagnant gas into the gas core region. Thus, the gas core region will eventually disappear because of the turbulent diffusion. During the turbulent diffusion process, the fluid momentum $M$ should be conserved along the bulk flow direction. When $U$ is local maximum velocity at any distance $x$ from the gas inlet, the momentum at $x$ becomes

$$
M=2 \pi \rho\left(r_{a}\right)^{2} U^{2} \int_{0}^{1}\left(\frac{\overline{u_{x}}}{U}\right)^{2}\left(\frac{r}{r_{a}}\right) d\left(\frac{r}{r_{a}}\right)=\text { cons tant }
$$

Hence, for a self-preserving flow pattern with profile similarity, Eq. (17) becomes

$$
U r_{a}=U x=\text { cons } \tan t
$$

The total flow rate $m$ at local distance $x$ is given by

$$
m=2 \pi \rho\left(r_{a}\right)^{2} U \int_{0}^{1}\left(\frac{\overline{u_{x}}}{U}\right)\left(\frac{r}{r_{a}}\right) d\left(\frac{r}{r_{a}}\right)
$$

When Eq. (18) is substituted for the local maximum velocity $U$ under a self-preserving velocity profile, Eq. (19) becomes 
$m=m_{o}+m_{1}=C_{o} r_{a}=C_{1} x \sim \frac{C v_{\text {eff }}}{U}$

In Eq. (20) $m_{0}$ and $m_{1}$ are gas flowrate at the inlet and total entrainment due to turbulent diffusion, respectively. The equation shows that total mass flowrate increases linearly with respect to the distance $x$ from the gas inlet from the stagnant surrounding fluid because of turbulent diffusion at the edge of the boundary layer. This is consistent with test results [10].

Figure 16 shows the modeling domain and boundary to simulate the experimental test conducted by Ricou and Spalding [10]. Detailed test conditions used for the modeling calculations are provided in Table 7. A three-dimensional turbulent steady-state approach was taken with the modeling boundary and conditions as provided by Fig. 16 and Table 7. The standard $k-\varepsilon$ turbulence model was used to estimate the turbulent entrainment driven by the gas jet. The calculations were performed with about 500,000 mesh nodes. The typical flow patterns for Case-5 conditions are shown in Fig. 17 . The corresponding mass fraction distributions for the $\mathrm{H}_{2}$ gas component at the center plane are also shown in Fig. 18. All the predictions of the six cases considered here are compared with the test results as shown in Fig. 19. The benchmarking results are summarized in Table 8 . The results show that the modeling predictions agree with the test data within about $19 \%$.

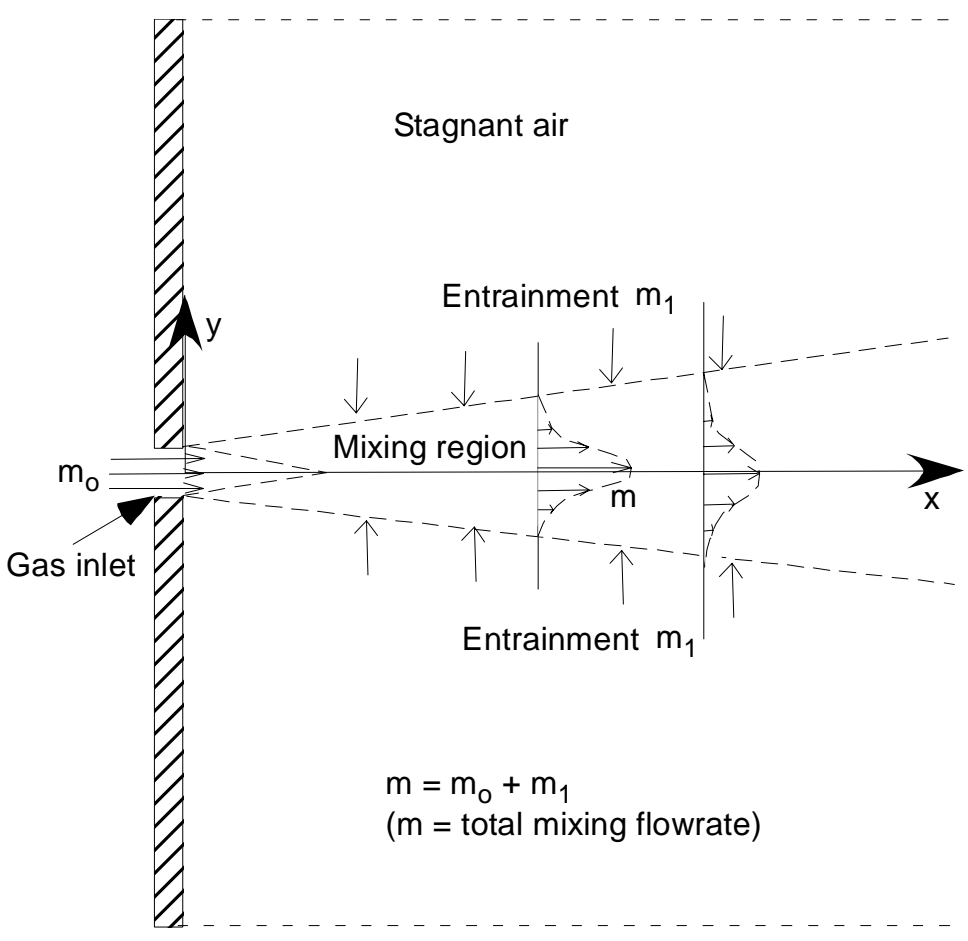

Figure 15. Gas entrainment due to turbulent diffusion in three-dimensional turbulent jet 


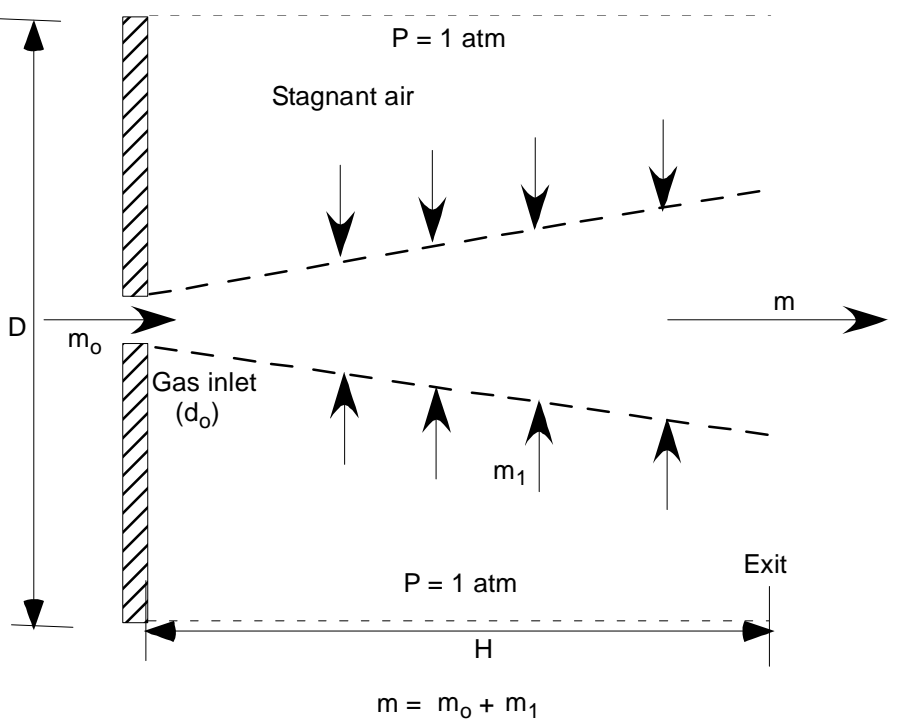

Figure 16. Test sections of Ricou and Spalding [10] as modeled for the benchmarking

Table 7. Test cases used for the modeling calculations

\begin{tabular}{|l|c|c|c|c|c|}
\hline Cases & $\begin{array}{c}\text { Gas } \\
\text { injected at } \\
\text { inlet }\end{array}$ & $\begin{array}{c}\text { Stagnant } \\
\text { gas in } \\
\text { chamber }\end{array}$ & $\begin{array}{c}\text { Inlet nozzle } \\
\text { diameter } \\
\text { (do, inches) }\end{array}$ & $\begin{array}{c}\text { Chamber } \\
\text { diameter } \\
\text { (D, inches) }\end{array}$ & $\begin{array}{c}\text { Chamber } \\
\text { Length } \\
\text { (H, inches) }\end{array}$ \\
\hline Case-1 & air & air & 0.0625 & 5.8 & 8.7 \\
\hline Case-2 & air & air & 0.625 & 5.8 & 8.7 \\
\hline Case-3 & air & air & 0.0625 & 8.9 & 3 \\
\hline Case-4 & air & air & 0.5 & 8.9 & 13 \\
\hline Case-5 & $\mathrm{H}_{2}$ & air & 0.5 & 8.9 & 13 \\
\hline Case-6 & $\mathrm{H}_{2}$ & air & 0.625 & 5.8 & 8.7 \\
\hline
\end{tabular}




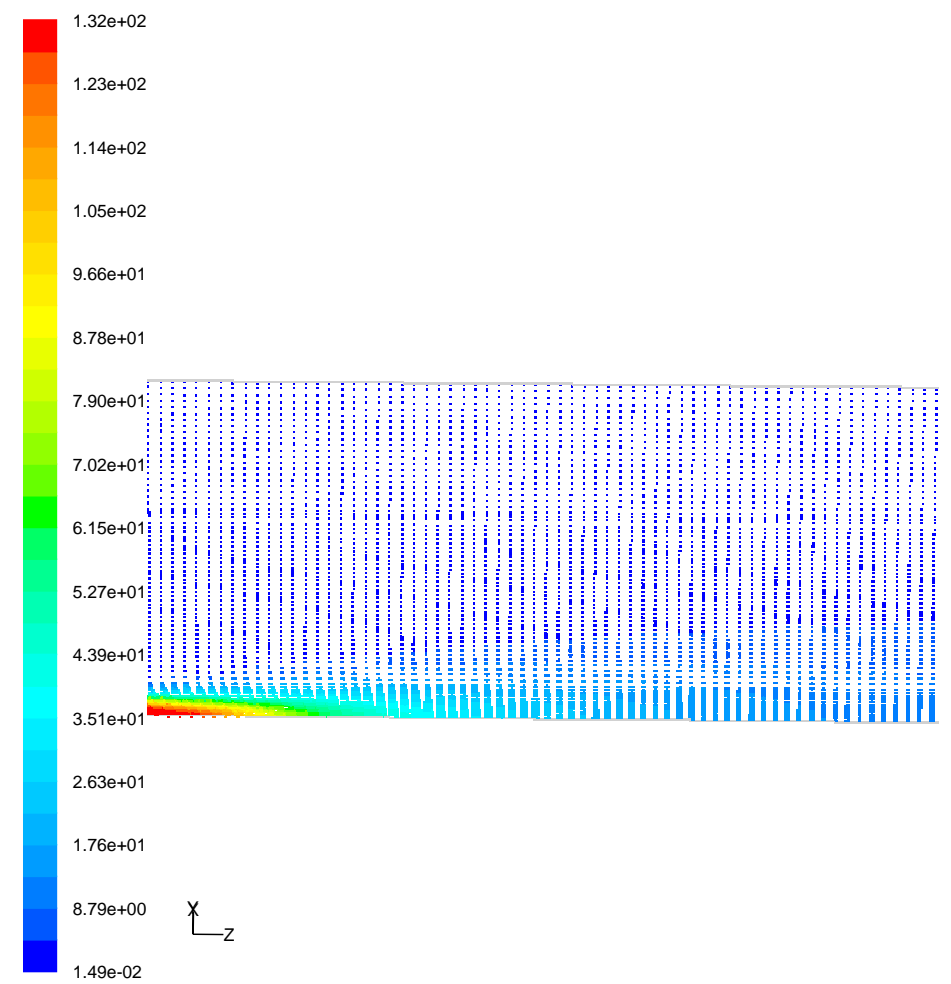

\begin{tabular}{|lr|}
\hline Velocity Vectors Colored By Velocity Magnitude (m/s) & Nov 21, 2005 \\
FLUENT 6.2 (3d, segregated, spe, ske)
\end{tabular}

Figure 17. Flow patterns along the center plane for Case-5 


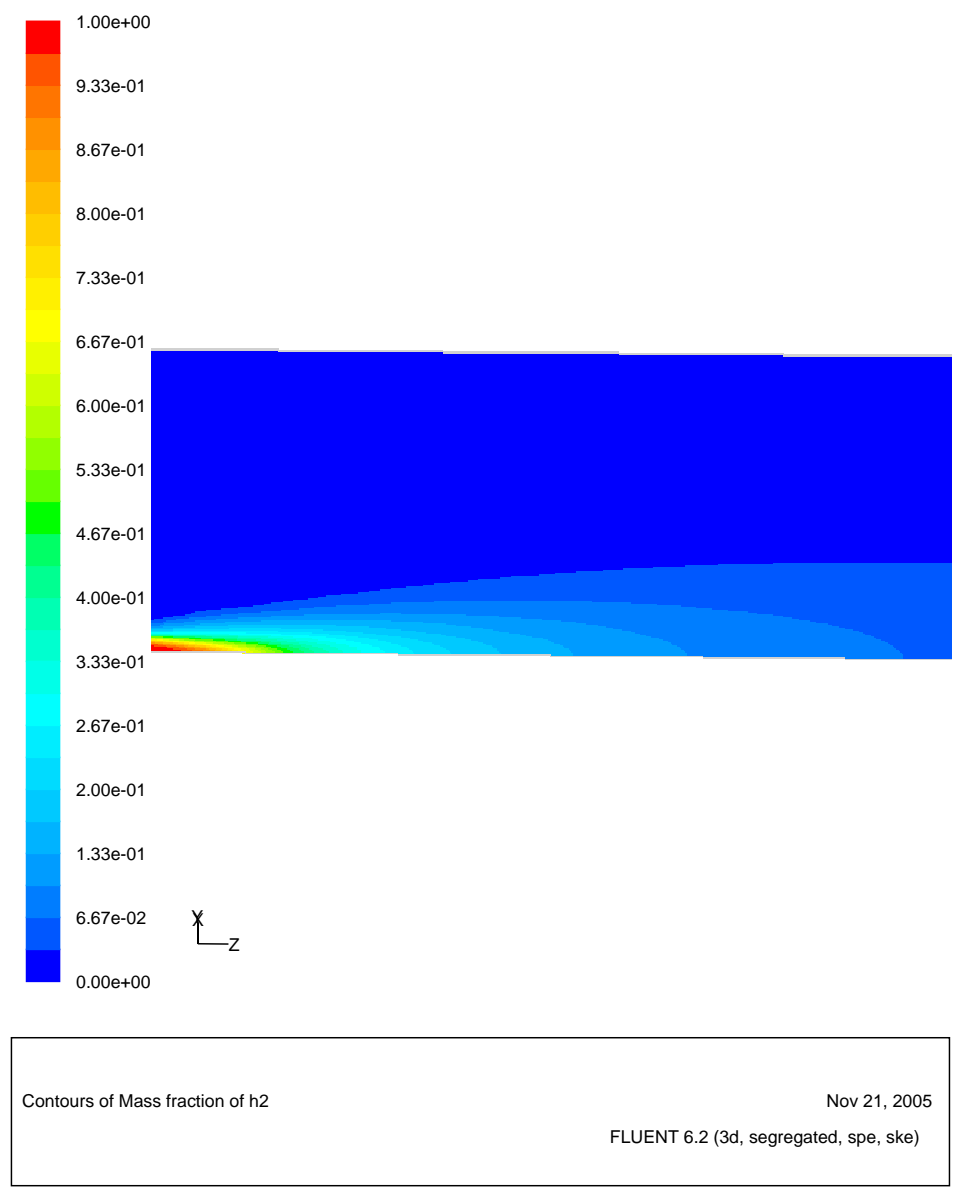

Figure 18. Mass flow fraction of the lighter gas component $\mathrm{H}_{2}$ gas along the center plane for Case-5 


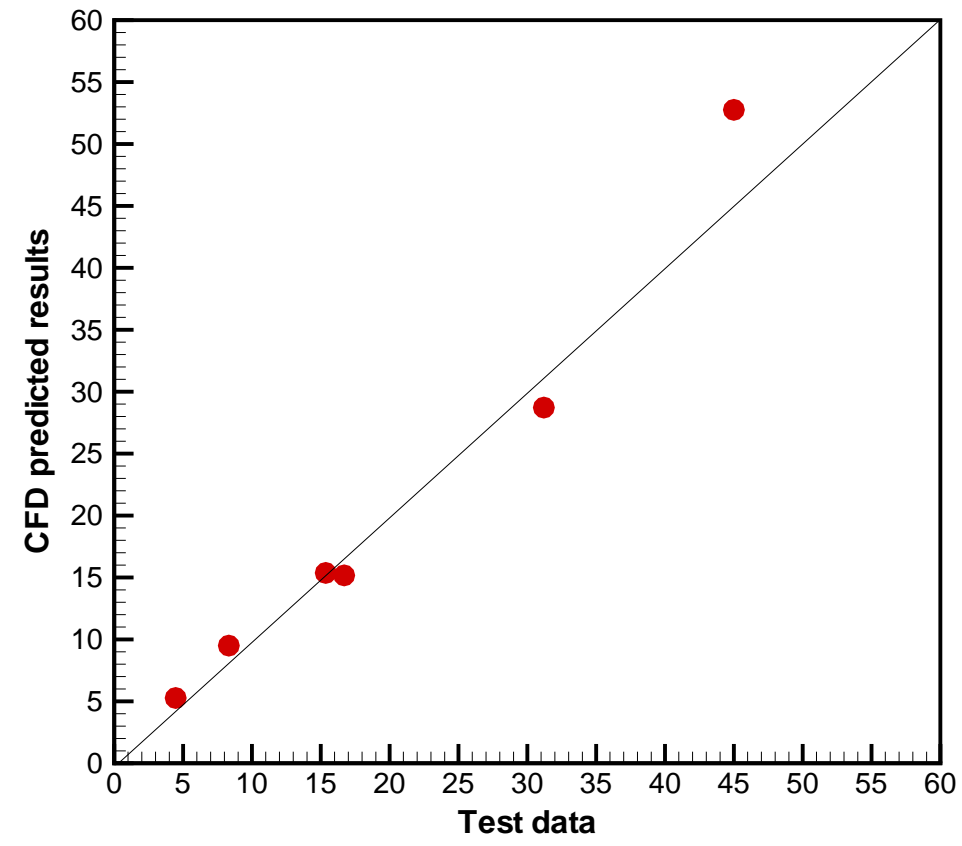

Figure 19. Comparison of the predictions with the literature data [Ricou and Spalding,1961]

Table 8. Bechmarking results of gas entrainments against test data [Ricou and Spalding, 1961]

\begin{tabular}{|c|c|c|c|c|c|}
\hline Cases & $\begin{array}{c}\text { Gas injected at inlet } \\
\text { (stagnant gas in } \\
\text { chamber) }\end{array}$ & $\begin{array}{c}\text { Reynolds } \\
\text { number, } \\
\operatorname{Re}^{*}\end{array}$ & $\begin{array}{c}\text { Test data } \\
\left(\mathrm{m} / \mathrm{m}_{\mathrm{o}}\right)\end{array}$ & $\begin{array}{l}\text { Predictions } \\
\qquad\left(\mathrm{m} / \mathrm{m}_{\mathrm{o}}\right)\end{array}$ & $\begin{array}{c}\text { Relative } \\
\text { error } \\
(\%)\end{array}$ \\
\hline Case-1 & Air (air) & $6.30 \times 10^{3}$ & 44.54 & 52.76 & 18.5 \\
\hline Case-2 & Air (air) & $3.73 \times 10^{4}$ & 4.46 & 5.27 & 18.2 \\
\hline Case-3 & Air (air) & $5.20 \times 10^{3}$ & 15.36 & 15.37 & 6.5 \\
\hline Case-4 & Air (air) & $3.00 \times 10^{4}$ & 8.32 & 9.50 & 14.2 \\
\hline Case-5 & $\mathrm{H}_{2}$ (air) & $1.63 \times 10^{4}$ & 31.20 & 28.72 & 7.9 \\
\hline Case-6 & $\mathrm{H}_{2}$ (air) & $2.10 \times 10^{4}$ & 16.70 & 15.17 & 9.2 \\
\hline
\end{tabular}

Note: * $\operatorname{Re}=\left(d_{o} \rho u_{0} / \mu\right)$ 


\subsection{Group3 Validation Problems}

The Group 3 validation problems don't deal with validating the Fluent code per se, but rather the model being employed for a specific application. In this case, mixing in the vapor space of Tank 48 (or 50), the ability of the code to adequately represent turbulence and diffusion phenomena has been addressed as a fundamental capability in the previous section. However, the model used to represent the tanks includes a critical assumption that has not yet been shown to be acceptable, viz., the assumption that the presence of the cooling coils in the tank can be neglected when evaluating the ability of a mixing jet to stir the entirety of the vapor space. The assumption is necessary because representing all of the cooing coils in a full scale model of the tank would be prohibitive both in terms of model size and in terms of computational run time. The following sections will show that the results from a full scale model without the cooling coils included are sufficiently accurate to infer the ability of the mixing jet to stir the tank.

\section{Impact of Small Flow Obstructions in a Large Flow Channel}

Before addressing mixing behavior in Tank 48, it is convenient to show that the impact of a group of small, cylindrical flow obstructions in a relatively large flow channel has only a minor impact of the overall flow in the channel. In addition, depending on the pattern of the obstructions, the overall velocity profile is relatively undisturbed.

As shown in Fig. 20, two different arrangements of flow obstructions were used to evaluate the impacts of flow obstructions on local flow velocities for a given air flow condition. Case-A has flow obstructions comprised of the tube array parallel to the bulk airflow direction, and Case-B has flow obstructions of staggered tube array. Both cases were three-dimensional evaluations that used typical bulk air velocity of $0.2 \mathrm{~m} / \mathrm{sec}$ based on the previous results under $150 \mathrm{cfm}$ recirculation rate. ${ }^{11}$ Most flow conditions under the prototypic Tank 48 system corresponds to the flow obstructions of Case-B due to the presence of cooling coil tubes. Each case considered two modeling conditions with and without flow obstructions. The flow obstructions were 2-inch tubes with spacing typical of the cooling coils in Tank 48. The calculated results for air velocity distributions on the flow domains are shown in Fig. 21. Table 9 shows that maximum deviation from the average air velocity under the staggered flow obstructions of Case-B is about $20 \%$ smaller than the parallel case of Case-A. The results demonstrated that the staggered pattern of Case-B results in a more uniformly distributed flow pattern than that of Case-A in terms of gas momentum dissipation. This results in better gas mixing under the same airflow rate (Fig. 22). These results are consistent with the literature results. [13] 
FLUENT Test and Verification Document

Page:

29 of 42
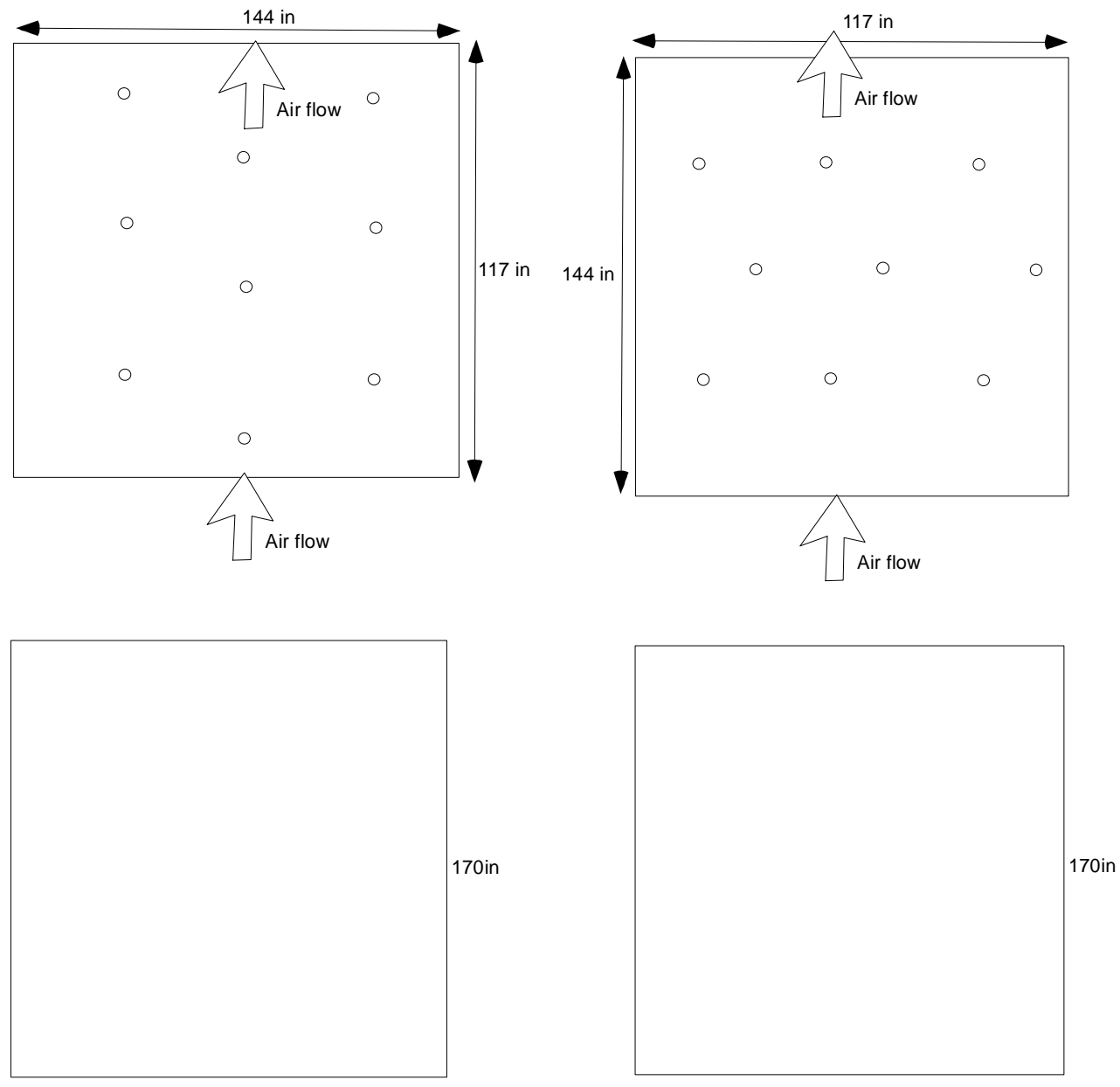

(Case-A)

(Case-B)

Figure 20. Modeling domains for two different flow directions passing over the flow obstructions (air inlet flow $=0.2 \mathrm{~m} / \mathrm{sec}$ from the previous calculations for $150 \mathrm{cfm}$ recirculation) 


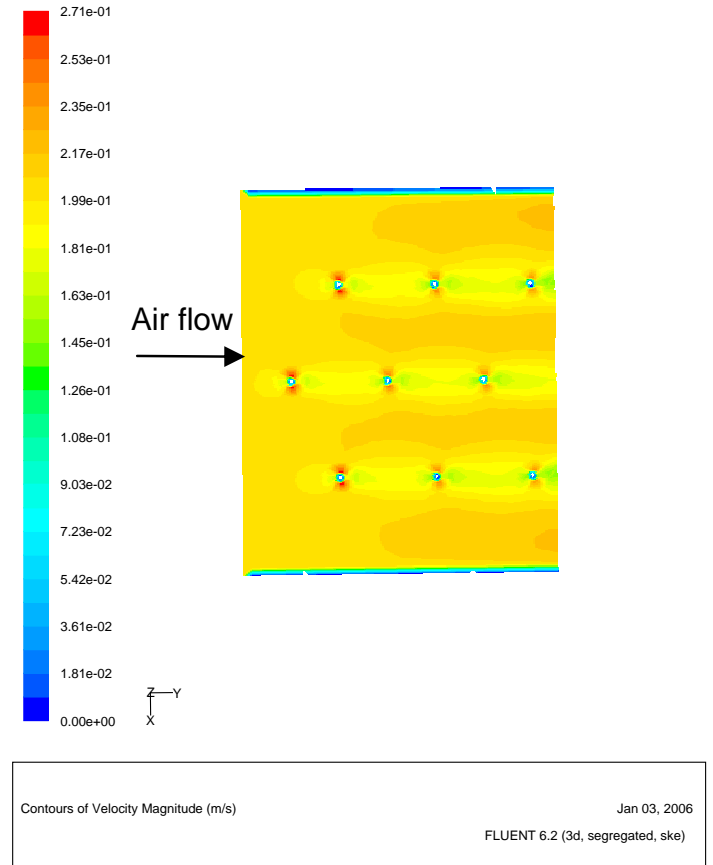

(Case-A: Flow with obstructions)

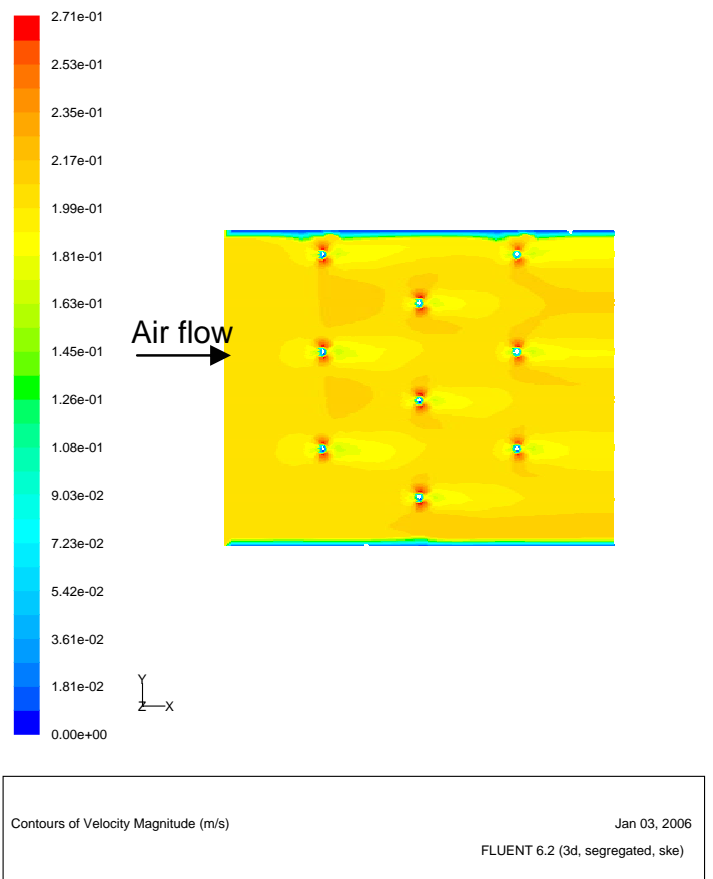

(Case-B: Flow with obstructions)

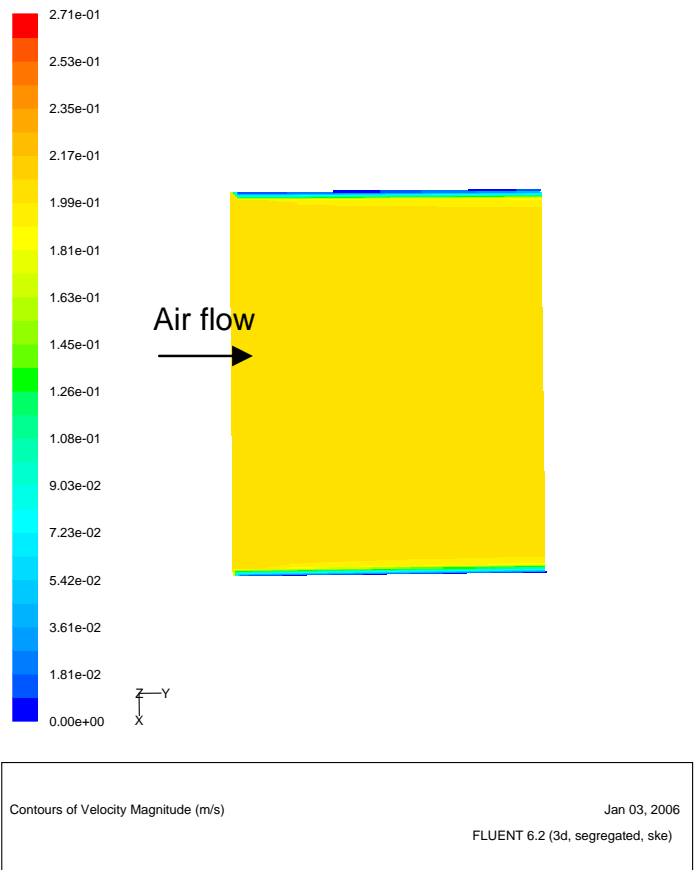

(Case-A: Flow with no obstructions)
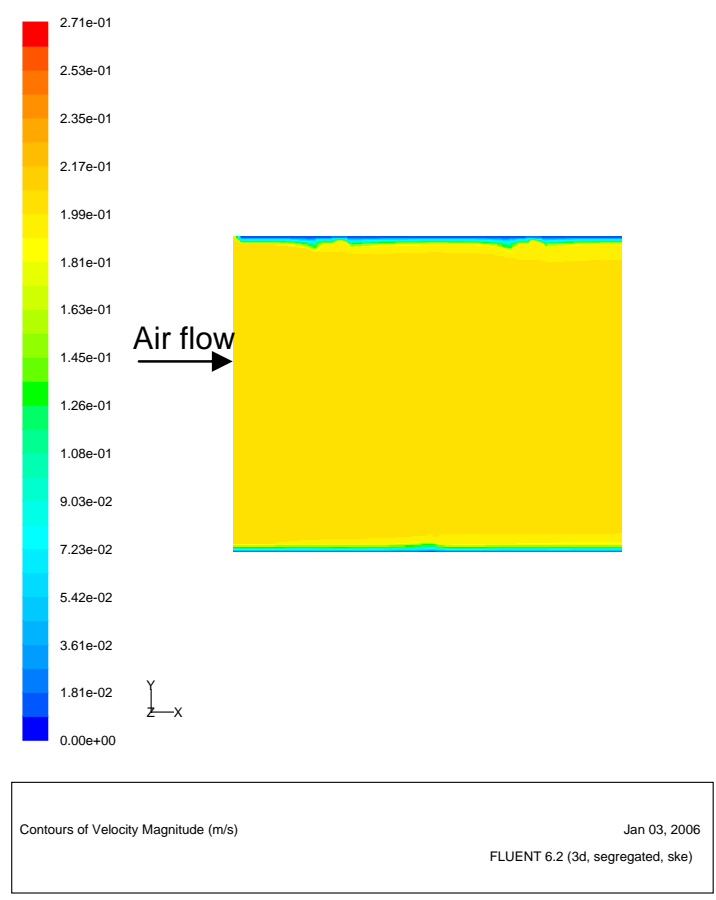

(Case-B: Flow with no obstructions)

Figure 21. Comparison of velocity contours between the two cases 


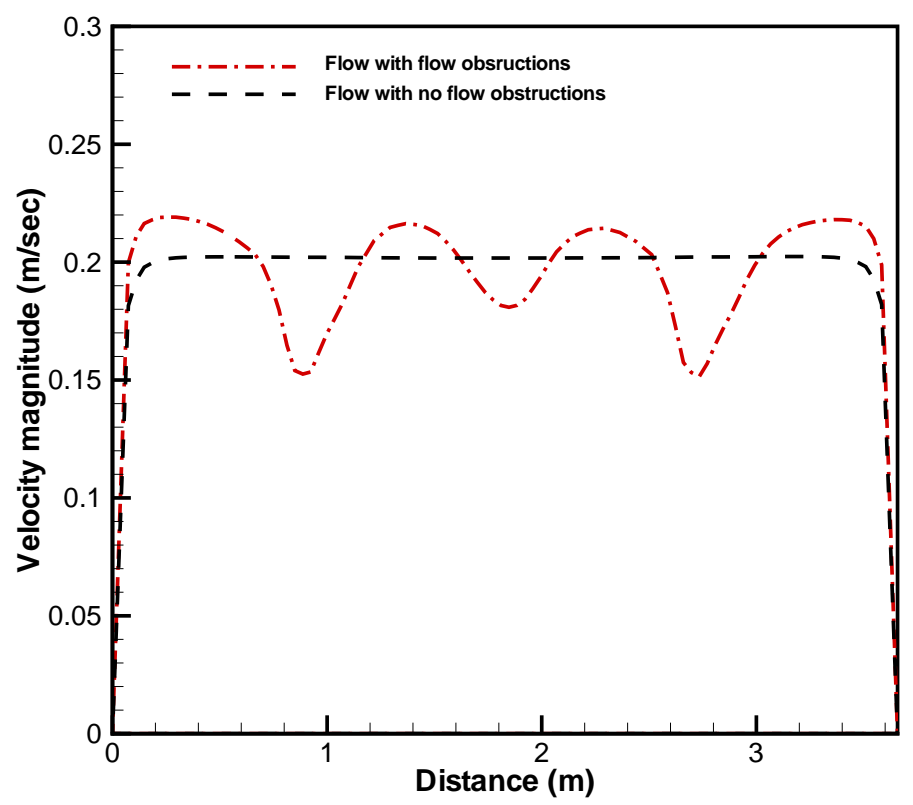

(Case-A)

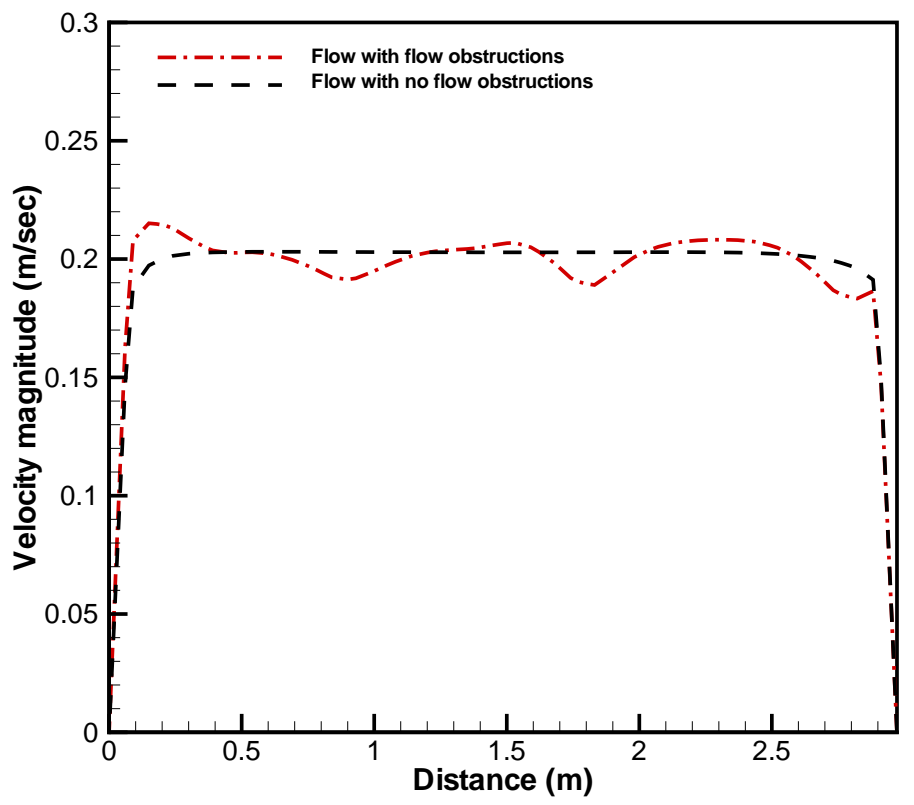

(Case-B)

Figure 22. Comparison of velocity magnitude at the mid-elevation of exit plane between the flow with and without the flow obstructions 
Table 9. Comparison for non-uniformity of maximum local velocities for a given gas flow condition of $5.0 \times 10^{4}$ Reynolds number

\begin{tabular}{|c|c|c|c|c|}
\hline Cases & $\begin{array}{c}\text { Flow obstruction } \\
\text { patterns to bulk air } \\
\text { flow }\end{array}$ & $\begin{array}{c}\text { Local max. or min. } \\
\text { velocity, } \\
\mathrm{m} / \mathrm{sec}\end{array}$ & $\begin{array}{c}\text { Average } \\
\text { velocity, } \\
\mathrm{m} / \mathrm{sec}\end{array}$ & $\begin{array}{c}\text { Max. \% deviation } \\
\text { of local velocity } \\
\text { from average } \\
\text { value }\end{array}$ \\
\hline Case-A & Parallel tube array & 0.15 & 0.2 & $25 \%$ \\
\hline Case-B & Staggered tube array & 0.19 & 0.2 & $5 \%$ \\
\hline
\end{tabular}

\section{Flow Obstruction Effects Due to the Presence of Cooling Coils}

The objective of this work is to investigate the impact of small, widely spaced pipes in a large tank, specifically the flow obstructions introduced by the 2-in cooling pipes inside the 85-ft cylindrical flow domain of Tank 48. The discussion immediately above showed that for a staggered pattern of flow obstructions, the overall flow pattern in the flow channel could be well represented by omitting the obstructions from the model. Because of the cylindrical geometry of Tank 48, this staggered pattern is representative of the cooling coils in the tank. By and large, the principally azimuthal flow passes a continually changing pattern of cooling tubes as it circulates around the tank.

It was also shown in the previous section that the pressure drop associated with the flow obstructions was small. In those calculations, the small pressure drop could be considered as significant because there was no other significant pressure loss available to limit the flow other than the drag associated with the channel walls. This relatively small pressure drop is not so important in Tank 48 for two reasons. The first is that the flow must turn as it reaches a tank wall and continues to recirculate. This recirculation introduces a turning loss that is large compared to the drag associated with the flow obstructions. Secondly, there is a significant energy transfer as the jet flow from the recirculating fan entrains the surrounding gas in the tank to drive the overall flow in the vapor space. Because of these facts, representing the tank as an open volume without the cooling coils captures the fundamental behavior of the gas flow in the tank, and the results calculated in Reference 11 provide a good representation of the mixing induced by the recirculating fan.

The results of Reference 11 showed that an internal fan recirculating gas in the vapor space at $150 \mathrm{cfm}$ provided good mixing within the vapor space and effective mixing of the benzene released from the liquid surface at a rate of $25 \mathrm{gm} / \mathrm{min}$. This calculation was performed with a model that did not include the cooling coils present in Tank 48.

To test the adequacy of the model used in Reference 11, a scaled model was developed that compared the effects of cooling coils to a similar model that did not include the coils. To provide a good comparison to the full-scale calculation in Reference 11, the scaled model was built around a power-scaling assumption, i.e., the power introduced into the tank by the recirculating fan was reduced by the ratio of the volume of the scaled tank to the full-scale volume. 
The scaled model was a tank 174 inches in diameter with an 8-in diameter center column. The scaled tank height was 35 inches. Tank 48 is 1020 inches (85 ft) in diameter, so the linear scaling factor is approximately 6 . The height of the vapor space was taken as 350 inches. Cooling coils were represented as 2 -in pipes, the same size as the actual pipes in Tank 48. Because of this, each row of pipes included in the scaled model represented roughly six rows of pipes from Tank 48. Since the drag on the flow passing the pipe is dependent on the circumference of the cylindrical pipe, linear scaling is appropriate for this parameter. The reason for using 2-inch pipes rather than reducing the diameter of the pipes by the linear scaling ratio was the same as the reason for not running a full-scale representation of the obstructed tank - the model would be too big to develop and too slow running to be useful.

Figure 23 shows a sketch of the scaled model with three rows of 2 -inch tubes included at the approximate radii indicated. The volume ratio of this scaled model to the fullscale, accounting for the excluded volume of the center column, is about 1/342. The ability of the mixing mechanism to stir the tank is generally determined by the power of the impeller, in this case, the gas flow introduced by the recirculating fan, relative to the volume of the tank. The power can be estimated by the rate at which kinetic energy is introduced into the tank by the fan. All other terms in the energy equation are small relative to this one.

The specific kinetic energy of the flow is $1 / 2 \rho v^{2}$, while the flow rate is $q_{\text {scaled }}=v A$.

Multiplying the specific kinetic energy by the volumetric flow rate gives the kinetic energy introduced by the fan, or

$$
\begin{aligned}
& \text { Power }=\frac{1}{2} \rho v^{2} q \\
& \text { Power }=\frac{1}{2} \rho v^{3} A
\end{aligned}
$$

Based on this relationship, the power added to the full-scale tank by the fan is 3.3 watts. Reducing this value for the scaled tank gives a power input of $9.69 \times 10^{-3}$ watts. The scaled flow introduced by the fan is the full-scale flow rate, $150 \mathrm{cfm}$, reduced by the volumetric scale factor of 342 , or $0.438 \mathrm{cfm}$. To estimate the flow velocity that might be expected at the center of the tank, it is desirable to keep the nozzle velocity that same as the full-scale velocity, or $8.7 \mathrm{~m} / \mathrm{sec}$. With this velocity, the scaled nozzle diameter is 0.216 inch.

The actual flow values used in the scaled tank model preserved the volumetric flow of $0.438 \mathrm{cfm}$, but the fan area was input as 0.25 inch. This resulted in a reducing exit velocity for the fan and an underscaled power by approximately $1 / 2$.

These scaled parameters were used to drive the calculations shown in Figures 24 and 25. They show that the obstructions in the scaled model have a noticeable impact of the distribution of flow, but not a detrimental impact on the mixing behavior overall. Both the velocity profiles and the turbulence intensities are similar with and without the obstructions.

This result was tested by relating the flow calculated by Fluent for the unobstructed tank to that which would be estimated by using handbook [14] values to estimate the turning losses in the tank. While no directly applicable geometry was found in the handbook by Idelchik [14], an approximation to the turning behavior in Tank 48 was developed by 
estimating the loss associated with a $180^{\circ}$ turn and then doubling the result. Diagram 6.1, Reference 14, was used to estimate a pressure loss factor of $\zeta_{\text {turn }}=4.25$ for the full $360^{\circ}$ turn in the tank. This represents an energy loss in the flow in the form of work that must be done to overcome the loss. It takes the form

$$
\zeta_{\text {turn }} \frac{1}{2} \rho v^{2}
$$

This can be expressed as a power by multiplying by the flowrate in the tank, $q=v A$, so that the power expended to overcome the turning losses is

$$
\frac{1}{2} \zeta_{\text {turn }} \rho v^{2} q_{\text {tank }}=\frac{1}{2} \zeta_{\text {turn }} \rho v^{3} A_{\text {tank }}
$$

This term is balanced against the power input by the fan as shown above. It can be expressed in terms of the inlet volumetric flow, $q_{i n}$, as

$$
\frac{1}{2} \rho \frac{q_{i n}^{3}}{A_{i n}^{2}}
$$

If the energy in the returning flow is subtracted as a source to the fan, the net power supplied by the fan can be balanced against the turning loss as (dropping terms of $1 / 2 \rho$ )

$$
\frac{q_{\text {in }}^{3}}{A_{\text {in }}^{2}}-q_{\text {in }} v_{\tan k}^{2}=\zeta_{\text {turn }} A_{\tan k} v_{\tan k}^{3}
$$

Equation (21) can be solved for a characteristic velocity in the tank depending on the assumptions used to interpret $v_{\text {tank }}$. The difficulty in using this simple analysis is that there is no single flow velocity that can be identified a priori that will give the correct total loss, nor does it capture the effect of fluid entrainment as the jet discharges into and entrains the surrounding gas. Nonetheless, the flow profile shown in Figure 26 shows that the maximum flow velocity located near the periphery of the tank is about five times the average flow velocity determined by dividing the integrated flow rate calculated by Fluent by the vertical cross-sectional area found by multiplying the tank radius by the liquid height. If the value of $v_{\text {tank }}$ in Equation (21) is expressed as $5 v_{\text {avg }}$, then the average flow rate calculated from Equation (21) is about 1.4 times the average flow rate calculated with the unobstructed Fluent model, i.e., the model without the cooling coils. This is considered excellent agreement given that the simple handbook approach:

1. assumes a single velocity, albeit one that was adjusted based on the calculated velocity profile from Fluent, and

2. does not account for the losses associated with the discharge jet from the fan spreading into the tank as it entrains the surrounding fluid.

The conclusion from this analysis is that the principal losses in the tank are indeed from turning the fluid, and that the small pressure losses calculated in the simple geometries in the previous section can be neglected when determining the overall flow behavior in the tank.

Having established the applicability of the unobstructed tank model, it is appropriate to evaluate the criterion used to develop the scaled model and demonstrate the similarity of the scaled model results to flow behavior in the full-scale tank. Recall that the power supplied by the recirculation flow was reduced by the volumetric ratio of the scaled tank 
to the full-scale tank, but that the nozzle exit velocity was kept at (approximately) the fullscale value. Figure 25 shows that the velocities at the midplane of the tank range from about $1.3 \mathrm{~m} / \mathrm{sec}$ close to the periphery of the tank and in the region that is strongly influenced by the jet discharge to a minimum of about $0.1 \mathrm{~m} / \mathrm{sec}$ close to the center column. A comparison with Figure 16 of Reference 11 shows similar velocities. The fullscale, unobstructed calculation shows velocities of about $0.5 \mathrm{~m} / \mathrm{sec}$ outside the range of the purge air inlet flow, but more importantly, minimum velocities of about $0.1 \mathrm{~m} / \mathrm{sec}$ near the center column indicating very good agreement with the scaled model results reported here.

It is also instructive to note the detailed results shown for the model with cooling coils in Figure 25. While the overall flow behavior is similar to the unobstructed case, the turbulence, therefore mixing, induced by the flow past the coils is evident in the flow patterns seen just downstream of several of the cooling coils. While this behavior does not represent an overall increase in the turbulent mixing in the tank - the losses introduced by the drag on the tubes result in a slightly lower flow rate - the increased turbulence that results in those losses themselves enhance the local mixing in the vicinity of the tubes.

The results of the flow comparisons with and without obstructions are summarized in Figure 26 and Table 10. Both the figure and the table show that the differences between the calculated results with and without obstructions are small, and that the unobstructed case gives a good representation of flow behavior in the tank. 


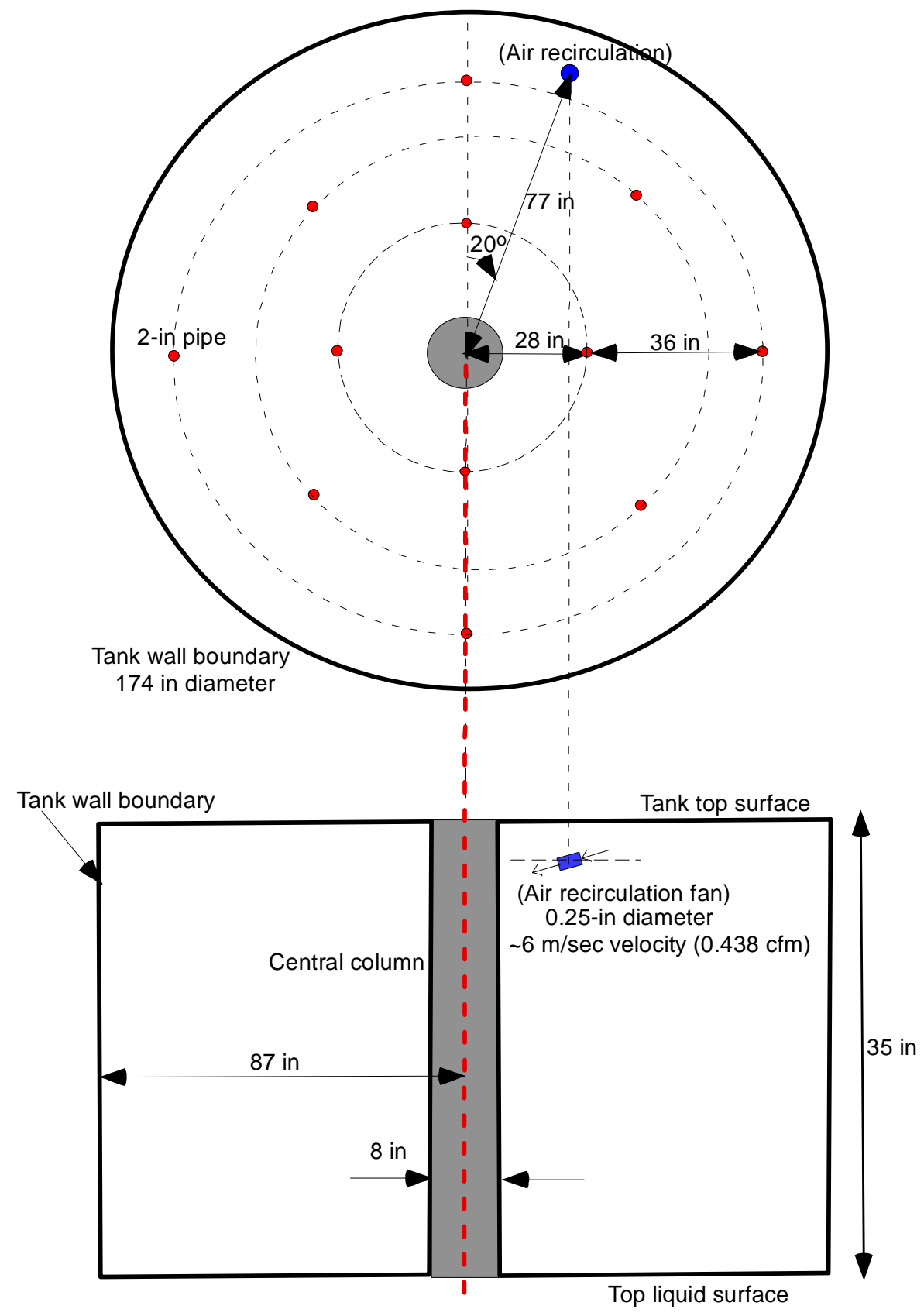

Figure 23. Modeling geometry for the internal circulation with flow obstructions under the larger domain system containing twelve 2-in pipes. 

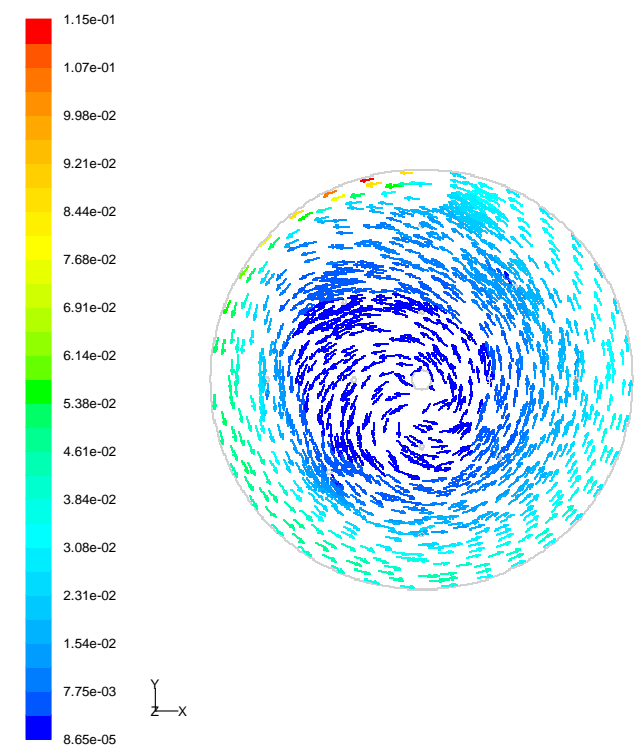

(Flow with flow obstructions)

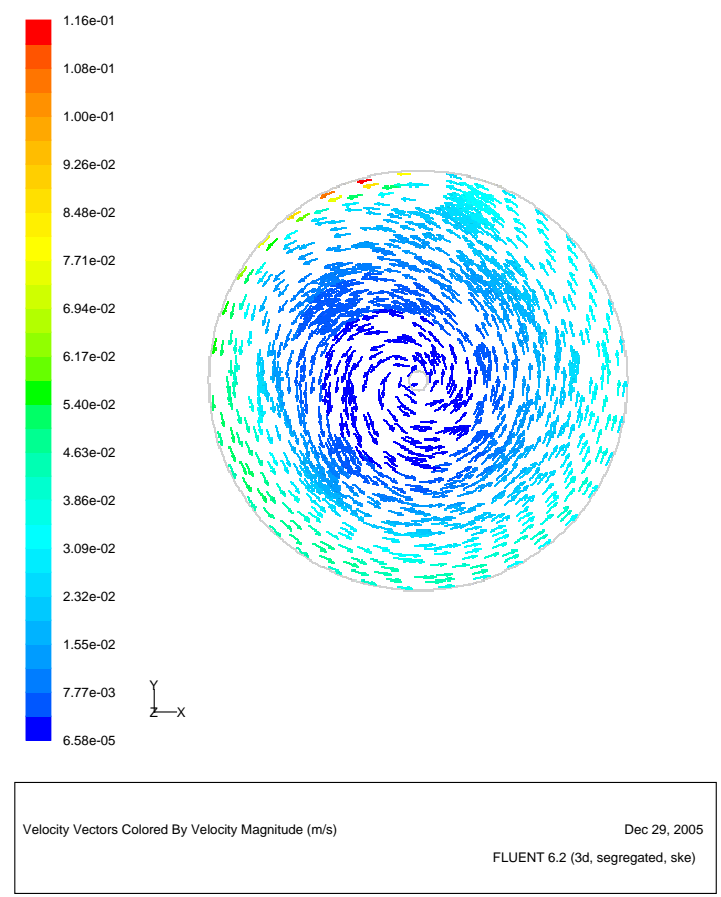

(Flow with no flow obstructions)

Figure 24. Comparison of flow patterns between the two cases at the mid-plane for the scaled domain system. 

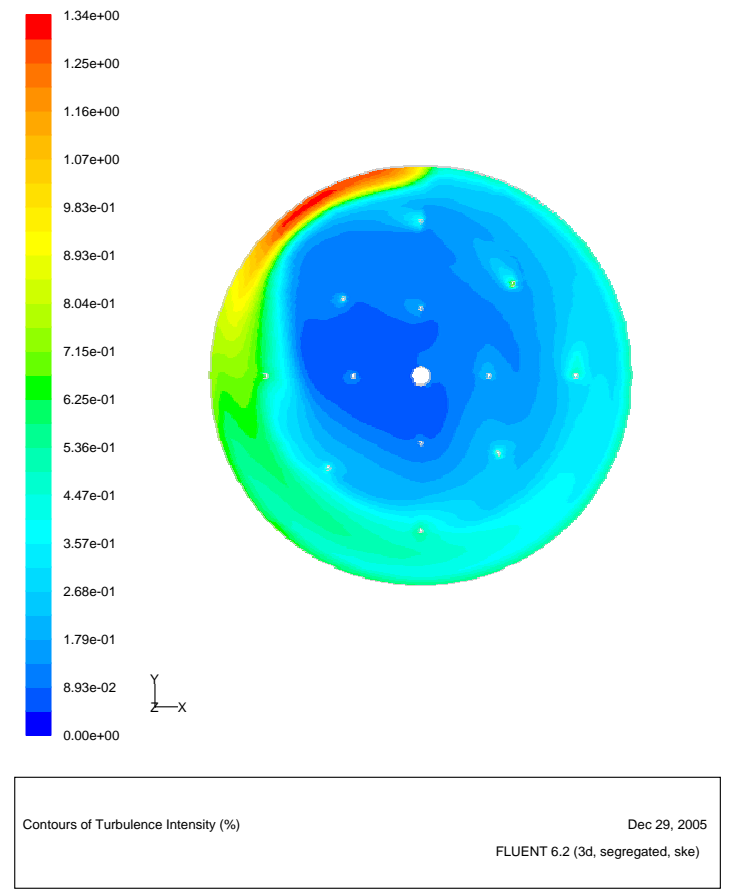

(Internal flow with flow obstructions)
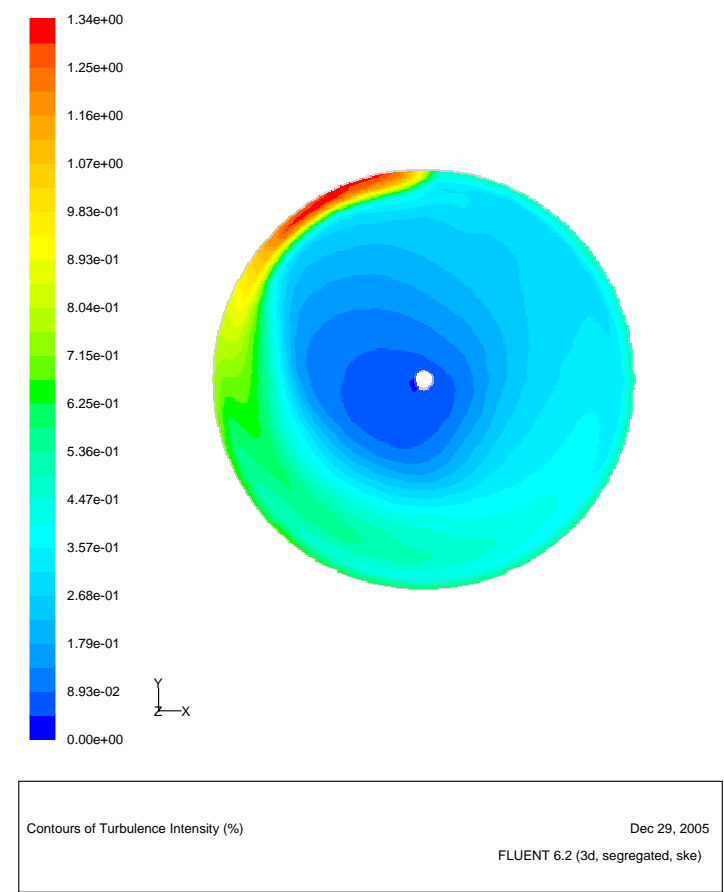

(Internal flow without flow obstructions)

Figure 25. Comparison of turbulent flow fluctuations between the flows with and without obstructions under $0.438 \mathrm{cfm}$ air recirculation in 174-in tank. 

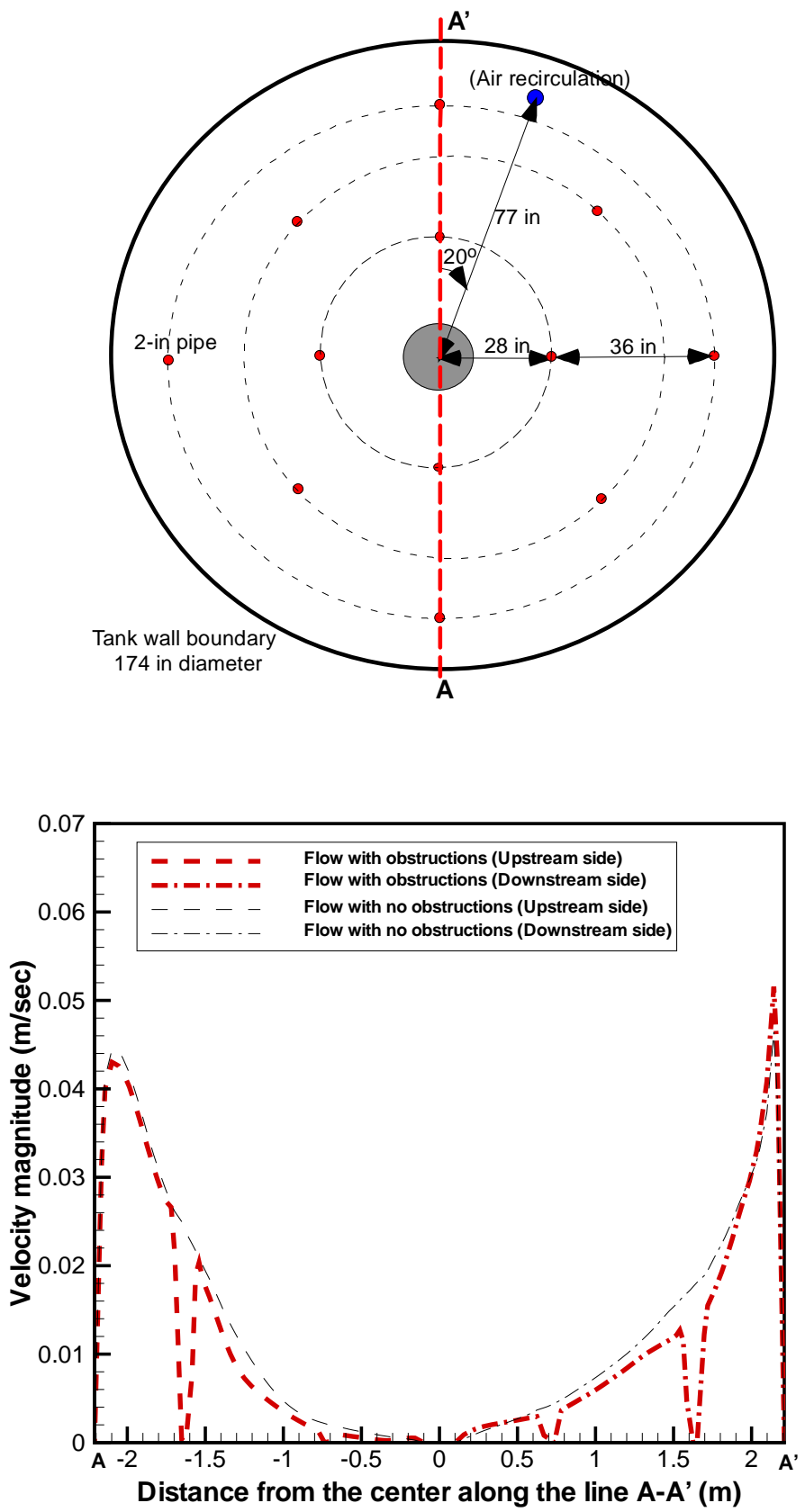

Figure 26. Comparison of velocity magnitude between the flows with and without obstructions under $0.438 \mathrm{cfm}$ air recirculation in 174-in tank. 
Table 10. Comparison of flow obstruction impact for the scale-down flow domain.

\begin{tabular}{|c|c|c|c|c|}
\hline $\begin{array}{c}\text { Flow system } \\
\text { domain } \\
\text { (Domain size: } \\
\text { 174-in diameter) }\end{array}$ & $\begin{array}{c}\text { Number of } \\
\text { 2-in coil } \\
\text { pipes in flow } \\
\text { domain }\end{array}$ & $\begin{array}{c}\text { Recirculation } \\
\text { flow in 0.25-in } \\
\text { pipe }\end{array}$ & $\begin{array}{c}\text { Max. velocity } \\
\text { at mid-plane }\end{array}$ & $\begin{array}{c}\text { Area-averaged } \\
\text { velocity }\end{array}$ \\
\hline $\begin{array}{c}\text { Flow with } \\
\text { obstructions }\end{array}$ & 12 & $0.438 \mathrm{cfm}$ & $0.101 \mathrm{~m} / \mathrm{sec}$ & $0.020 \mathrm{~m} / \mathrm{sec}$ \\
\hline $\begin{array}{c}\text { Flow with no } \\
\text { obstructions }\end{array}$ & 0 & $0.438 \mathrm{cfm}$ & $0.101 \mathrm{~m} / \mathrm{sec}$ & $0.022 \mathrm{~m} / \mathrm{sec}$ \\
\hline
\end{tabular}

Note: Reynolds number corresponding to the flowrate is about $1.1 \times 10^{4}$.

\section{Summary}

The FLUENT 6 CFD code has been benchmarked for a wide range of simple, classical, and complex physical problems associated with hydraulics or turbulent mixing phenomena. The benchmarked problems consisted of two main groups. The first group was well-defined and classical problems for which analytical solutions exist. The other one is complex and physical problems for which analytical solutions are difficult to obtain. For these test problems, CFD results are compared and verified through comparisons with experimental results.

The test results of the FLUENT 6 code showed that the code predictions are in good agreement with analytical solutions or experimental test data. The code predictions for the first group agreed with solutions or data within about $10 \%$ relative error. For the complex test problems of the second group, the code predictions agreed with the literature data within about $18 \%$ relative error.

A third class of problems was evaluated for the specific application to the vapor space of Tank 48 (and Tank 50). These problems were focused on particular scaling and phenomenological issues, notably the impact of obstructions on vapor space mixing, to validate the application of an unobstructed tank model to mixing behavior in Tank 48 . The results showed that the application is valid and that the effect of the cooling coils can be neglected when evaluating the ability of an internal mixing fan to stir the vapor space. An extension of this work will be required to generalize the applicability of Fluent to further vapor and liquid mixing analyses in waste tanks where the bounding assumptions of the present analysis cannot be satisfied. This would include higher contaminant (benzene) concentrations or more complex geometries where the adequacy of the $k-\varepsilon$ model has not been demonstrated. 


\section{References}

1. Abramovich, G. N., The Theory of Turbulent Jets, M.I.T. Press, Cambridge, MA, 1963.

2. Bird, R. B., Stewart W. E., and Lightfoot, E. N., Transport Phenomena, John Wiley \& Sons, New York, 1960.

3. Ansley, T. E., "FLUENT 6 Installation and Test", e-mail memo to Holding-Smith, C. P. , December 16, 2005 (See attachment)

4. Flow of Fluids through Valves, Fittings, and Pipe, Engineering Div., CRANE Co., New York, 1976.

5. W. M. Rohsenow and H. Y. Choi, Heat, Mass, and Momentum Transfer, PrenticeHall, Inc., Englewood, N. J., 1961.

6. Kays, W. M. and Crawford, M. E., Convective Heat and Mass Transfer, Second Edition, McGraw-Hill, Inc., New York, 1980.

7. Kiser, K. M., "Material and Momentum Transport in Axisymmetric Turbulent Jets of Water", A.I.Ch.E. Journal, Vol. 9, No. 3, pp. 386-390, 1963.

8. Nielsen, P. V., Restivo, A., and Whitelaw, J. H., "The Velocity Characteristics of Ventilated Rooms", J. of Fluids Engineering, Vol. 100, pp. 291-298, 1978.

9. Lee, S. Y. and Dimenna, R. A., "Validation Analysis for the Calculation of a Turbulent Free Jet in Water Using CFDS-FLOW3D and FLUENT (U)", WSRC-TR-95-0170, May 1995.

10. Ricou, F. P. and Spalding, D. B., "Measurements of Entrainment by Axisymmetrical Turbulent Jets", Journal of Fluid Mechanics, Vol. 11, pp. 21-32, 1961.

11. Lee, S. Y. and Dimenna, R. A., "Additional Scoping Calculations of Tank 50 and Tank 48 Vapor Space Mixing”, WSRC-TR-2005-00533, October 2005.

12. Forstall, W., Jr. and Shapiro, A. H., "Momentum and Mass Transfer in Coaxial Gas Jets", Journal of Applied Mechanics, pp. 399-408, December 1950.

13. Thatcher, T. L., Wilson, D. J., Wood, E. E., Craig, M. J., and Sextro, R. G., "Pollutanty Dispersion in a Large Indoor Space: Part 1 - Scaled Experiments Using a Water-filled Model with Occupants and Furniture", LBNL-50248, Lawrence Berkeley National Laboratory, 2003.

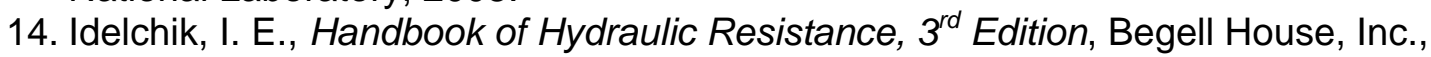
New York, 1996.

15. Dimenna, R. A. Interoffice Memorandum to B. K. Taylor, "Glass Waste Storage Building Natural Circulation Analysis," SRT-EMS-950088, December 6, 1995.

16. Nielsen, P. V., "Flow in Air Conditioned Rooms," (English translation of PhD thesis from the Technical University of Denmark, 1974), Danfoss A/S, Denmark 1976 (cited in Nielsen et al. [8]) 
Page: $\quad 42$ of 42

\section{Attachment: FLUENT 6 Installation and Test}

THOMAS ANSLEY/WSRC/SRS

12/16/2005 02:09 PM

TO CYNTHIA HOLDING-SMITH/SRNL/SRS@SRS

CC SI LEE/SRNL/SRS@SRS

SUBJECT: FLUENT 6.X INSTALLATION AND TEST

Cynthia,

ITD personnel installed and tested Fluent 6.x executables on the IBM Risc6000 platform running AIX 5.1.

thanks,

Thomas E Ansley 